\title{
The Structural Optimization of Ceramic Fuel Cells
}

\author{
Oleksandr Vasylyev", Mykola Brychevskyi, Yehor Brodnikovskyi
}

Frantcevych Institute for Problems of Materials Science, Ukraine

Copyright $\bigcirc 2016$ by authors, all rights reserved. Authors agree that this article remains permanently open access under the terms of the Creative Commons Attribution License 4.0 International License

\begin{abstract}
The paper addresses questions concerning the structural optimization of ceramic fuel cells (CFC) aiming to increase the ionic conductivity realized at long term operation of zirconia electrolyte in the very structure of CFC applying scandia as the stabilizer of zirconia cubic phase and electron beam physical vapor deposition as the production method of the CFC's electrolyte film. Its chemical composition would be optimized in a course of a few iteration processes of a substance transfer from virgin powders into the electrolyte phase of CFC laminated composite, which is changed by diffusion processes between CFC electrolyte and its electrode layers during CFC production and long-term operation. The final, optimized, chemical composition and structure of entire CFC would be tuned by taking into account the structural altering occurring during both production and operation.
\end{abstract}

Keywords Ceramic Fuel Cell, SOFC, Boundaries, Electrical Conductivity, Mechanical Behavior, 1Ce10ScSZ Zirconia Powders, EB-PVD, Structural Optimization

\section{Introduction}

Ceramic Fuel Cell (CFC), or in their probably first definition - Solid Oxide Fuel Cell (SOFC), is a high temperature device that converts the chemical energy of fuel and oxidant's interaction into electricity and heat through electrochemical reactions, i.e. directly with no any intermediate conversions.

Thereby, CFC as a fuel cell system can offer very high electrical efficiencies (twice as high as traditional converters, for instance, heat machines). They offer perspectives to decreasing fuel consumption for stationary (local combined heat and power, CHP), mobile (auxiliary power units, APU, or hybrid vehicles), or portable (battery replacer) applications, as well as reducing $\mathrm{CO}_{2}, \mathrm{NO}_{\mathrm{x}}$ and other pollutant emissions due to both much higher efficiency of energy conversion and comparatively low operating temperature. No moving parts are involved in the energy conversion process and, thus, valves and air blowers comprise the only moving parts in the fuel cell system, which improves reliability and increases safety in the application.
At its very beginning, thanks to at least three of its pioneers - Humphrey Davy (1802), Christian Schoenbein (1838) and William Grove (1845), the fuel cell has been born and invented as a typical chemical device consisting of liquid aqueous electrolyte and two platinum electrodes placed in a vessel.

It was logical that the idea of the ceramic fuel cell was begun realizing as some analog of a fuel cell based on liquid electrolyte - as a set of solid parts, namely solid electrolyte, and anode and cathode electrodes applied to electrolyte as well as some interconnect. All the CFC parts were chosen as the best from the point of view of their properties to meet operating functions.

The solid oxide electrolyte is a principal substance of the CFC because namely this component makes the fuel cell phenomenon feasible. The solid electrolyte prevents the direct interaction of gases, fuel and oxygen, and does their reactions controlled in time and place, and not capable of an explosive behavior.

Readers could find the fascinating histories on solid electrolyte and fuel cell developments in [1-4].

The very idea of "the solid electrolyte" goes probably back to the time of Henry Cavendish (1774) who had observed an increasing conductivity of glass on heating. The early stage of solid oxide development is closely associated with particular activities of prominent scientists such as H. Davy (1802), who probably was the first who formulated the very idea of fuel cell, Michael Faraday (1833) with his well-known research on electrolytes, and Jean-Mathee Gaugain (1853), who discovered galvanic solid electrolyte gas cells. The need in solid electrolytes has grown in the late $19^{\text {th }}$ century when Pavlo Jablochkoff (1877), Wilhelm Ostwald (1894) and others have been developing fuel cell electrodes that could withstand aggressive liquid electrolytes such as molten alkali carbonates in order to realize the idea "Electricity Directly from Coal" that was then popular, and that, by the way, begun to be interesting now again [5].

In fact, the first SOFC in its current understanding was developed by Emil Baur and H.Z. Preis in 1937 [6]. For its electrolyte, they had used the so-called Nernst-mass (85-wt. \% $\mathrm{ZrO}_{2}+15$-wt. $\% \mathrm{Y}_{2} \mathrm{O}_{3}$ ) following Walter Nernst (1897), who applied it in production of his incandescent lamps for filaments (glowers) [7-9].

Since that, during more than century, the modified 
Nernst-mass is practically the best ceramic electrolyte for high and $600{ }^{\circ} \mathrm{C}$ temperature fuel cells [10].

The current science and technology on fuel cells are based on properties of individual materials those make up them, though, the fuel cell phenomenon is realized by the whole fuel cell. The fuel cell consists of electrolyte and two electrodes, anode and cathode, which provide transportation of gases to the electrolyte and electrons to an external electric network. In total, the fuel cell has to ensure a stable long-term course of chemical reaction between the fuel and oxidizer.

The CFC is not being constructed from its individual parts joined between them mechanically. The CFC is being constructed as a single unit, in which the solid (ceramic) electrolyte is in an intimate mechanically inseparable contact with the electrodes. The basic chemical reactions between fuel and oxidant gases releasing useful electrical and heat energies occur at points of the electrolyte-electronic conductor-pore contacts. Taking into account its support that carries a thin, comparatively weak mechanically, CFC and its electrical contacts, such a system is a polyfunctional laminar composite, properties of which must be considered as the properties of the single unit. It is obvious that in order to secure the cell integrity and electrical contacts between cell layers their thermal expansion mismatch must be minimized. However, this important task is facilitated by the fact that the electrolyte material being as an ionic conducting part of both electrodes is forming a zirconia-ceramic skeleton made of one material. An electronic conductor of electrode is clinging to its ionic conductor through its open pores.

If CFC is built as supported on any electrode, the main property of electrolyte is its density and ionic conductivity. The near $100 \%$ density is required in order to prevent any direct interaction of fuel and oxidant gases. They may react being only in ionic states exclusively. The attention is concentrated on ionic conductivity and its temperature dependence. According to these indicators, a chemical composition, which could ensure the necessary number of oxygen vacancies in electrolyte crystal and transportation of oxygen across it, is been chosen. Nano- and microstructures are influencing significantly on the ion movement that is why their impact is studied intensively.

If a fuel cell is built on the electrolyte as a holder of the whole CFC, the importance of electrolyte mechanical behavior is obvious also.

CFC is a high temperature device for very long operation, term of which is defined by decades of years. After European developers have exceeded the requirements of the US Department of Energy about 40,000 hours ( 4.5 years) of the SOFC operation life, the European Horizon 2020 program has begun to demand more than 25 years?! At such the conditions, it more than obvious that knowledge on effect of temperature and time of operation on fuel cell behavior is required in order to predict possible long term changes of entire fuel cell energy systems.

And finally, in CFC that is a high temperature device, the main part of which - electrolyte resides in a direct intimate contacts with electrodes under an electric tension of $\sim 0.7-1.0$ $\mathrm{V}$, and hedges off reducing and oxidizing atmospheres. The thickness of the gas-tight electrolyte layer in the fuel cell consists of $5-10 \mu$. Namely through this thin partition membrane, the transportation of oxygen ions, which may move in ionic crystal along chains of oxygen vacancies only, occurs. It is obvious that properties of this electrolyte film must be high and stable as possible.

CFCs are being made currently using high energy technologies, sintering or deposition from a vapor state, which facilitate interdiffusion between structural components. In typical sintered CFCs, this phenomenon was noticed for quite some time ago and doping of electrolyte by chemical elements from adjacent electrodes, first of all, $\mathrm{Ni}$, $\mathrm{Mn}, \mathrm{La}$ and $\mathrm{Cr}$ was detected there [11-19 and others]. In the CFCs made with electron beam - physical vapor deposition (EB-PVD) technique, the same reveals itself much faster.

At EB-PVD, the deposition process of electrolyte film of 10-15 $\mu \mathrm{m}$ onto $\mathrm{NiO}-\mathrm{ZrO}_{2}$ porous anode substrate lasts comparatively quickly, $10-20 \mathrm{~min}$, its initial composition is distorted significantly due to diffusion of $\mathrm{Ni}$ and $\mathrm{Y}$ from the substrate. The amount of $\mathrm{Ni}$ in $1 \mathrm{Ce} 10 \mathrm{ScSZ}\left(\mathrm{ZrO}_{2}-\right.$ 10 -mol. \% $\mathrm{Sc}_{2} \mathrm{O}_{3}-1$-mol. \% $\mathrm{CeO}_{2}$ ) electrolyte is more than 2 -wt. $\%$ at the anode-electrolyte interface. It means that amount of dopants negatively influencing on oxygen ionic conductivity is higher than might be admitted from the point of view of a phase stability of zirconia stabilized with scandia. As result, the conductivity of EB-PVD 1Ce10ScSZ film deposited on NiO-YSZ substrate is much lower ( one order of magnitude) than might be expected from the data on conductivity of bulk samples [19].

What does happen in the electrolyte film produced by traditional ceramic technique without application of electron beam is still unknown. It is known only that electrical properties of CFC become worse notably during the first 100-200 hours of operation. During this term, the electrolyte conductivity of bulk samples made of nano-powders decreases respectively. Then, the properties become practically unaltered for above 1500 hours [20]. Such the behavior might be as a result of completing structural equilibration in the CFC composite for so short time. It is quite possible too that the equilibration processes could occur much faster at EB-PVD method of the CFC production.

The similar processes take place in CFC electrodes. Their progress is burdened by gas atmospheres.

Anyhow, the above listed results in degradation of $\mathrm{CFC}$ properties. And, despite the obvious importance, they are not studied yet in a full measure in order to be used for further enhancement of $\mathrm{CFC}$ and prediction of their long-term behavior [21].

CFC is composed of sintered polycrystals structurally, boundaries and properties of which are as important as their bulk. In opinion of authors, the study of boundaries, their complexions and transitions, and their effect on electrochemical, that is as if obvious, and mechanical 
behaviors is the key to understanding of CFC properties, properties of entire device and its separate materials and their improvement after that. The main thing of this study is to get the necessary number of samples and tools for their processing that could provide the necessary set of material parameters to be suitable for a study and data comparison.

As our research practice says, the sufficient set of boundary properties could be ensured with different powder types and temperatures of their sintering for some fixed time.

As to sintering temperature, it is easy question. The typification of powders is much heavier task. It requires huge ponderous comprehensive comparative structural research of ceramics made of different powders of comparatively the same chemical composition. Fortunately, the first crop has been harvested already.

The goal of the paper was to analyze the data accumulated on structure of $1 \mathrm{Ce} 10 \mathrm{ScSZ}$ solid bulk electrolyte made of three types of powders and sintered at different temperatures, and thin EB-PVD electrolyte film, and its mechanical behavior related to grain boundaries, which could be revealed with biaxial bend loading and scanning electron fractography, and grain boundary electrical conductivity to be revealed with impedance spectroscopy, and formulate a concept of structural optimization of the CFC based on scandia stabilized zirconia operated at $600{ }^{\circ} \mathrm{C}$.

\section{Materials and Methods}

10Sc1CeSZ (1-mol. \% $\mathrm{CeO}_{2}-10$-mol. \% $\mathrm{Sc}_{2} \mathrm{O}_{3}-$ $89-\mathrm{mol}^{\circ} \% \mathrm{ZrO}_{2}$ ) ceramics that is considered now as the most promising electrolyte for CFC was made of three types of $10 \mathrm{Sc} 1 \mathrm{CeSZ}$ zirconia powder of formally the same chemical composition, but using different initial raw materials and synthesis conditions resulting in different morphology, impurities composition and distribution. The powders were subjected to comprehensive characterization with traditional analytical techniques and analyzed in numerous literature.

The typification of powders has its origin in their morphological and chemical features, morphological and mechanical properties of their agglomerates, ability to be sintered and mechanical behavior of their ceramics consolidated with uniaxial and cold isostatic pressing. The listed properties were obtained at comparative studies. The Type I powder (developed by V. Vereshchak and produced at Vilnohirsk Mining \& Metallurgical Plant and Zirconia Ukraine Ltd., Ukraine) was made by co-precipitation technique; the Type II powder delivered by Daiichi Kigenso Kagaku Kogyo, DKKK, Japan, was produced, as we could know, by the hydrothermal synthesis, and the Type III powder delivered by Praxair, USA, was made by spray-pyrolysis.

The structural and mechanical properties of these powders, the methods of manufacturing as well as the comparative results were reported earlier [20, 22, 23 etc.]. Here, we remind only that the Type I powder is agglomerated in $\sim 2.5$ $\mu$ semisoft-semirigid creatures of rod-like morphology consisting of $11 \pm 2 \mathrm{~nm}$ initial particles; the Type II is practically non-agglomerated and consist of soft $73 \pm 20 \mathrm{~nm}$ particles of a isotropic morphology, and the Type III is agglomerated in $\sim 1.3 \mu$ rigid ceramic husk-like creatures, which are, in fact, as thin plates of well-sintered ceramics. For easier discussion of data, the electron microscopy pictures of the powders are gathered in Figure 1.

The powders were milled in alcohol for $24 \mathrm{~h}$ using $\mathrm{ZrO}_{2}$ ceramic balls and left to dry in air. Afterwards, $10 \mathrm{Sc} 1 \mathrm{CeSZ}$ powders with no any sintering aids were uniaxially pressed at $30 \mathrm{MPa}$ into discs of $20 \mathrm{~mm}$ in diameter and $1.5-2 \mathrm{~mm}$ thick. The samples were sintered in the temperature range of $1250-1550{ }^{\circ} \mathrm{C}$ for $1.5 \mathrm{~h}$ in air using VK 1600 , Linn High Term furnace (Germany). Strength of the as-sintered samples was measured with biaxial bend loading technique at the self-made installation. The fracture surfaces of the samples were observed with the scanning electron microscope (SEM, Superprobe 733, JEOL).

Materials and methods of ceramics characterization are described in details in [20, 23 and others]. Here, we would like to remind that the initial carriers of dopants, contaminants or impurities are surfaces of initial particles and their agglomerates. During sintering they are redistributing between grains and their boundaries forming grain boundary complexions, which are transforming in the courses at their heat treatment at sintering. As to features of chemical composition of samples obtained with a wet-technique, the concentration of impurities in the bulk made of the Type I and the Type III powders is around $0.01-w t . \%$. The Type II is much purer; it contains only 0.001 -wt. \% of impurities. Regarding the nature of the contaminants, the Type I is contaminated mainly with silica $(0.05 \%)$ and alumina $(<0.025 \%)$ while in the Type III mainly silica $(0.05 \%)$ and titania $(<0.14 \%)$ are present. Additional minor contamination in the form of $\mathrm{K}, \mathrm{Na}, \mathrm{Ca}$, and Fe was also found in Types I and III powders. From the point of surface-bulk distribution obtained with secondary ion mass spectroscopy, in the Type II, the surface of particles is enriched with $\mathrm{Sc}$ and $\mathrm{Al}$; in the Type III, Sc and $\mathrm{Si}$ are mostly present on the surface. In the Type I, the surface is depleted with Sc; while Sc and Si are mostly localized in the bulk of the particles.

The electrical impedance of the samples was measured as a function of AC frequency using a Solartron 1260 impedance/gain-phase analyzer within the frequency range of $10^{-2}-10^{6} \mathrm{~Hz}$ at $600{ }^{\circ} \mathrm{C}$ in air. For these measurements, the silver paste electrodes were deposited onto the sample surface and sintered. The diagrams were modeled by means of electrical equivalent circuits (EC), which consisted of two or three parallel RC-circuits and a resistor connected in series, and analyzed in $[24,25]$. As a result, the model parameters such as the resistances and capacitances of the grains and grain boundaries, Ohmic resistances, and the parameters $(\alpha, \Theta$ and $\beta)$, which reflect the deviation of the impedance spectra from the Debye's view, were obtained.

\section{Results and Discussion}


The data on bulk electrolyte are expounded first. They are followed by the data on EB-PVD thin electrolyte film, its nucleation and growth mechanisms as instruments of nano-size structure formation to be suitable for 3D microionic construction and structural optimization of the CFC. The discussion is completed by formulation of a concept of structural optimization of the zirconia ceramic fuel cells.

\subsection{Scandia Stabilized Zirconia and Related Problems}

The realization of high oxygen ionic conductivity of solid electrolytes based on zirconia to be ensured with scandia is facing at least two problems.

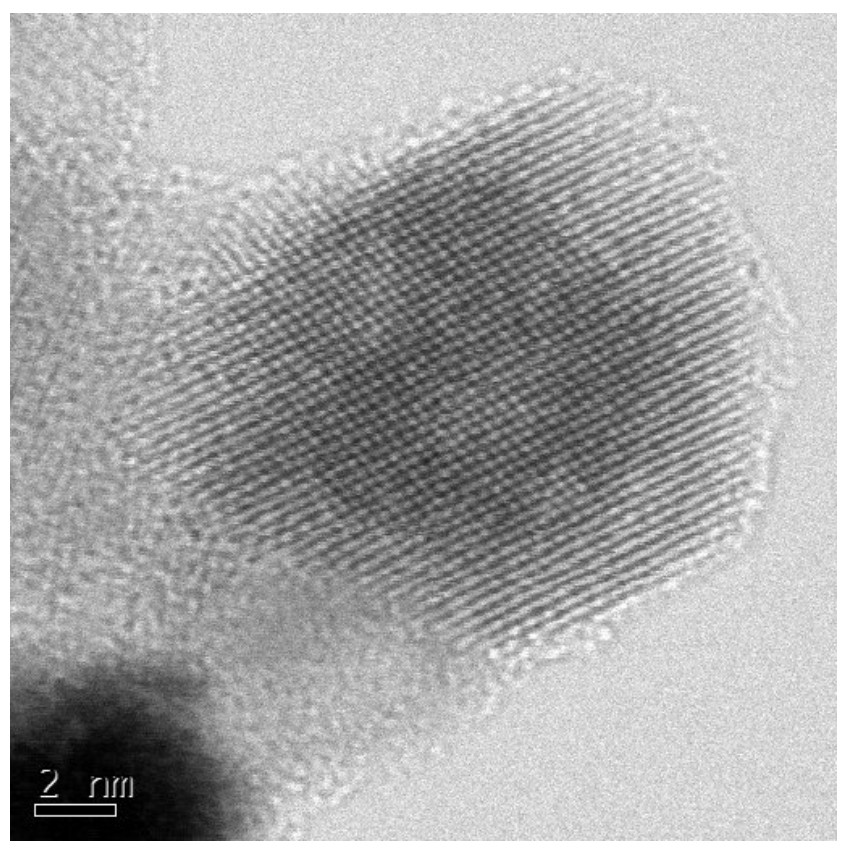

A
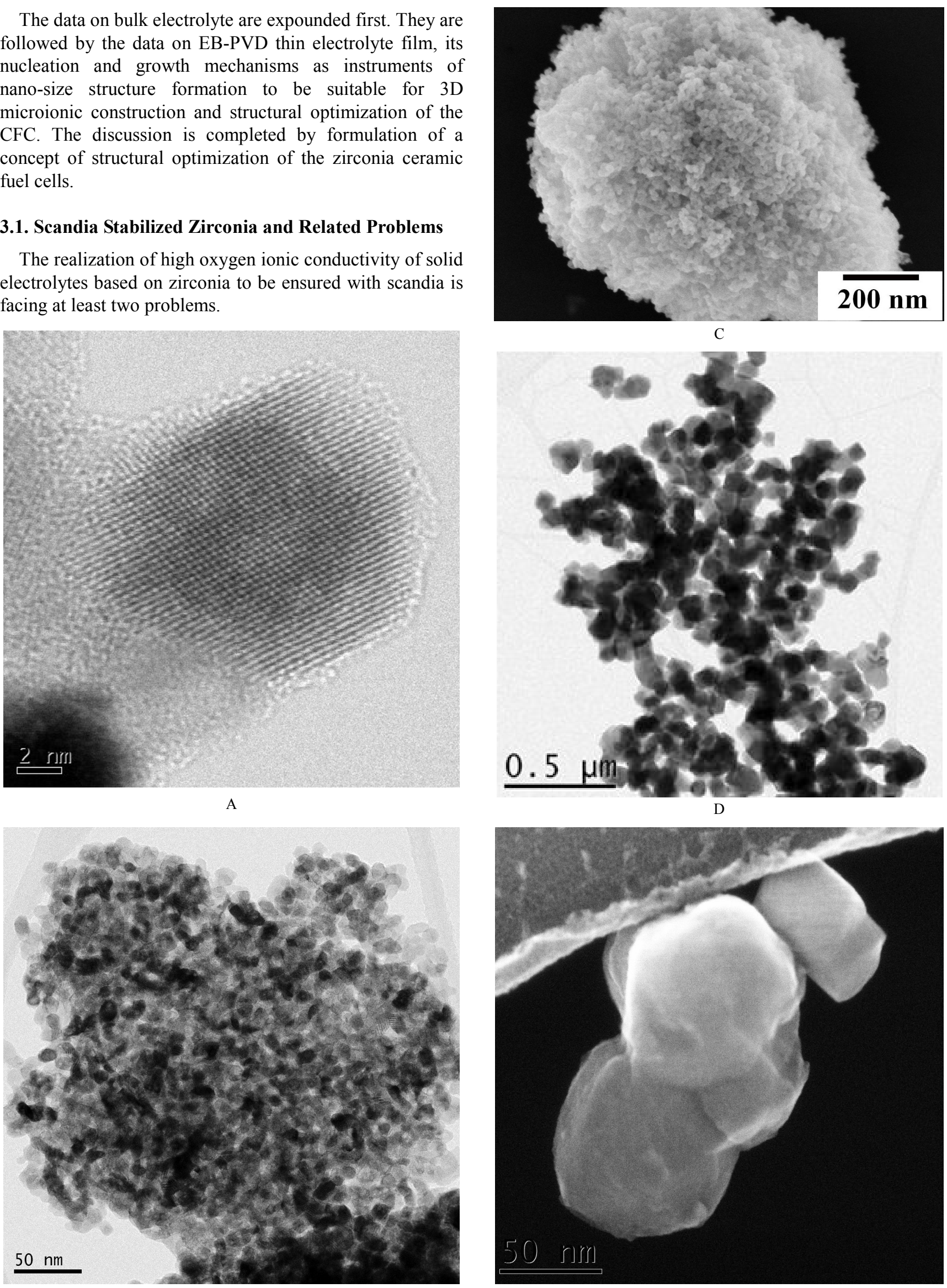

E 


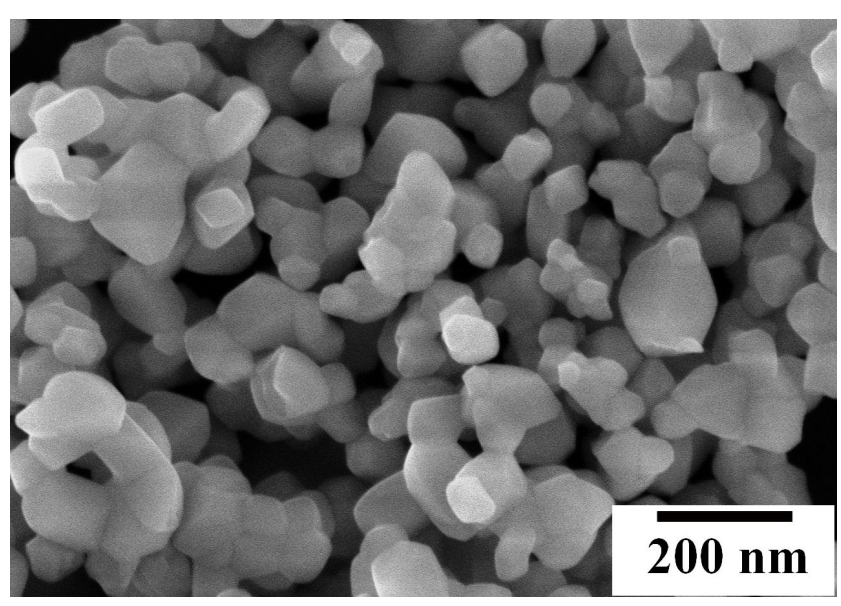

F

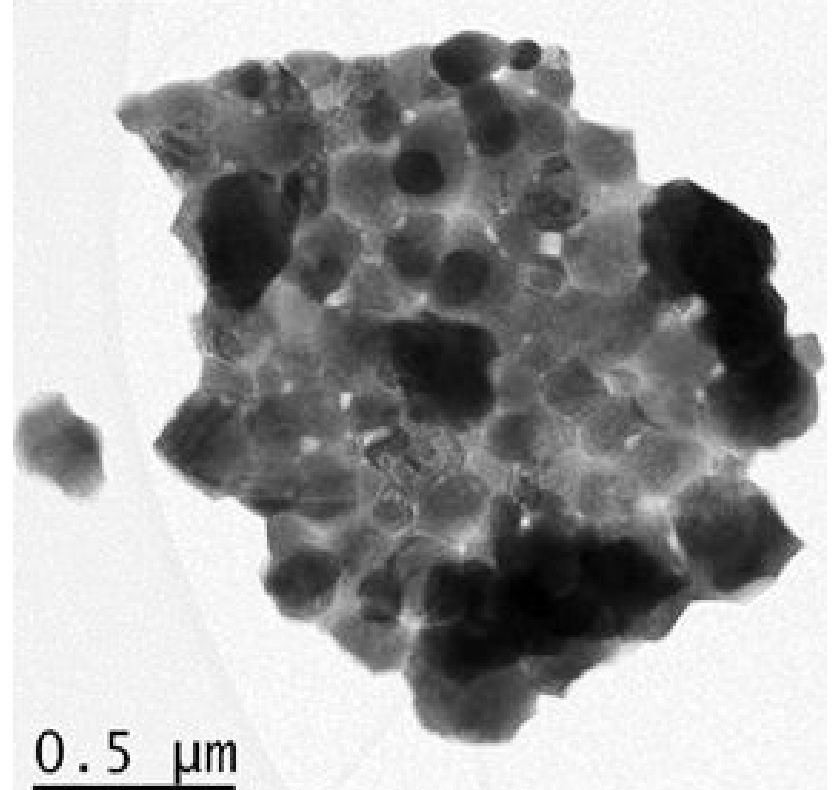

G

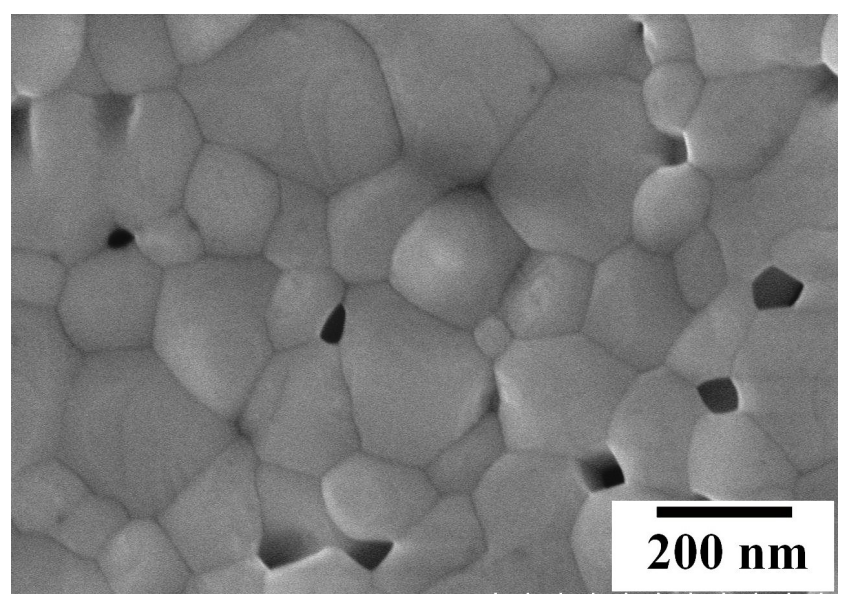

$\mathrm{H}$

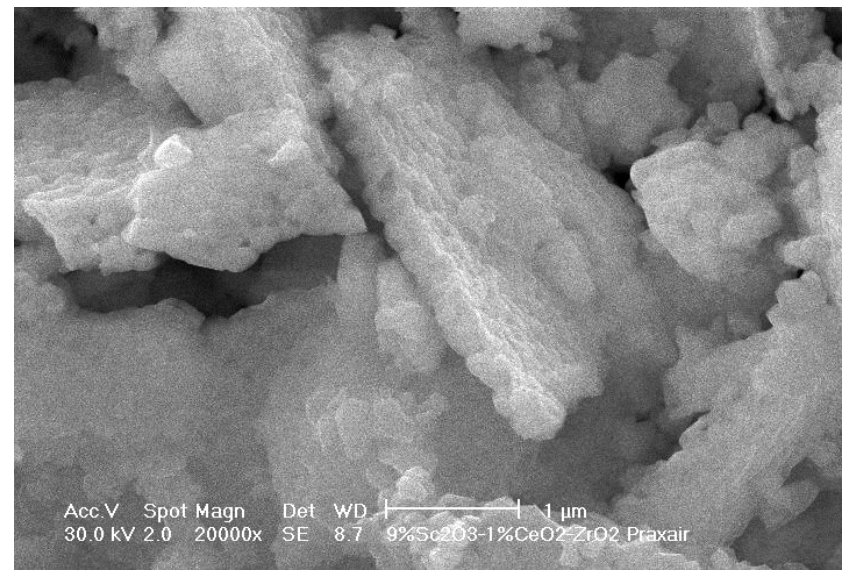

I

Figure 1. The high-resolution (A), conventional transmission (B,D,G) and scanning (E,F,H,I) electron microscopy images of three 10Sc1CeSZ powder Types (A,B,D-F) and their agglomerates (C,G-I). A-C - Type I, D-F - Type II, and G-I - Type III [20,22].

The first one is a comparatively old problem of high temperature structural instability of scandia stabilized zirconia (SSZ) that results from arising in it high resistance phases $[26,27]$. The problem is solving by additional doping of zirconia with $\sim 1-\mathrm{mol} . \%$ of the second stabilizer like ceria, alumina, titania etc. But the second doping decreases the conductivity significantly, reasons of which are still unclear. Both, chemical composition of electrolyte and its structure are not optimized yet. The first problem is related to electrolyte material that is considered as a separate substance, which is beyond the fuel cell, i.e., it has no direct contacts with electrode materials and is not loaded by high temperature gases, which are different at each side of electrolyte plate.

The second one is a comparatively "fresh" problem, which became considered only recently. It is determined as chemical and structural instability of electrolyte arising in it in a course of both production of CFC and its long term high temperature operation. It is clear that the first problem is a part of the second one, where the electrolyte material is not only influenced by temperature, but its thin layer gets in contact with other materials by high energy method and exposes to reducing and oxidizing gases through contacting gas permeable porous electrode materials for a long time.

The second problem is a degradation problem of film electrolyte essentially, which is placed in a structure of laminated composite and exposed to aggressive high temperature environments, which are different on its both sides. Moreover, the electrolyte film is nucleating and growing on supporting electrode material from vapor phase of electrolyte material excited by electrons.

This problem is not only unstudied yet. It is only now formulated. 
It sets the tasks to study as follows:

- How does electrolyte condense from the vapor phase and grow on the porous heterogeneous substrate?

- What is happening with electrolyte film when it is exposed by cathode material?

- What is happening with a material of rather thin $(<10$ $\mu \mathrm{m})$ electrolyte film, which is placed between two different materials of electrodes, anode and cathode, during a comparatively short time of production at temperature above $1000{ }^{\circ} \mathrm{C}$ in air at conventional technological $\mathrm{CFC}$ route and vacuum, in the case of application of EB-PVD technique?

- What is happening with electrolyte film during long term (thousands hours) operation at, e.g., $600-800{ }^{\circ} \mathrm{C}$ being exposed by reducing or redox atmospheres (fuel) at one side (anode) and oxidizing atmosphere (air) at another side affected through permeable materials of corresponding electrodes?

We know already that the electrolyte film of $\sim 20 \mu \mathrm{m}$ thickness being deposited by EB-PVD technique on $\mathrm{NiO}-\mathrm{ZrO}_{2}$ anode during a rather short (less $30 \mathrm{~min}$ ) time deposition process is enriched with nickel, concentration of which near the anode-electrolyte interface consists of around 2-wt. \% and around 1-wt. \% near free film surface [19,28,29]. We see that electrolyte film is not only structurally but also chemically heterogeneous, in which, e.g., $\mathrm{Ni}$, as well as $\mathrm{Y}$ that is not shown here, a gradient distribution across the film thickness occurs. There are some data pointing out that $\mathrm{NiO}$ could stabilize cubic structure of zirconia acting similar traditionally used $\mathrm{CeO}_{2}$ etc. [30-32], and this phenomenon is proposed to be used for correlation of the electrolyte composition. The similar phenomena occur probably on a cathode side of the electrolyte also.

The analogous changes in solid phases take place in the anode. Moreover, this phenomenon is enhanced under the action of hydrogen [33-35].

As to cathode, there are still no reliable data on its influence on structure of the electrolyte film.

Considering zirconia-based electrolyte materials as polycrystalline, it is usually believed that silica is decreasing conductivity of zirconia due to its segregation along grain boundaries. The logic is simple: smaller grain size - larger specific grain boundary surface - purer boundary - higher conductivity. However, as to silica, we see, the Type II electrolyte is generically more pure (more than one order of magnitude $-0.004-w t . \%$ in it - against 0.05 -wt. $\%$ in the Type I or the Type III ones). The similar situation is observed with alumina. Suppose that segregation of silica along grain boundaries has increased indeed due to grain growth during around 150 hours that results in significant conductivity decrease observed. After this term, the conductivity of the silica doped electrolyte becomes unchangeable vs. time and equal to the conductivity of the purer electrolyte that is the Type II one.

Thus, zirconia based electrolyte of technical purity, doped with silica and alumina, ensure the same level of conductivity similar to its more pure analogue. In that time, there are some structural states of $10 \mathrm{Sc} 1 \mathrm{CeSZ}$ electrolyte that ensure significantly higher conductivity. However, this high level of conductivity is suppressed by elements, which are mutually diffusing between electrolyte and electrodes that takes place at both production of $\mathrm{CFC}$, especially when EB-PVD technique is used, and during its operation that is probably promoted by hydrogen.

The cases mentioned are saying that in order to keep the ionic conductivity high enough and stable or even increased at a long time of operation, chemical composition and structure of electrolyte film might be optimized or, saying by another words, be correlated by taking into account their changes during both making the CFC, especially with EB-PVD technique, and its operation at real environments. The correlation of electrolyte consists in modification of some initial chemical composition, which could be changed during the CFC production process and some (not very long) term of the CFC operation or its training, in order to produce finally some "ideal" composition that could ensure the best conductivity, which, additionally, might be even improved during operation instead of a traditional decrease with time.

In such a way, the electron beam might be considered as the effective tool of quick electrolyte modification that is able also to change the concepts of both the zirconia powder selection for electrolyte and the CFC production.

\subsection{Structure and Properties of the Bulk Electrolyte}

Structural parameters of sintered materials depend on sintering temperature $T_{\mathrm{s}}$. It is obviously that a dependence of strength $\sigma$ and mechanical behavior in general on sintering temperature might be defined as some function of structural constituents, first of all, porosity $\mathrm{P}$, grain size $\mathrm{d}$ and some property $\gamma$, something like the surface energy, which describes quality of boundaries between structural constituents and depends on amount and ordering of admixtures along them.

In general, following [36], the strength $\sigma$ in dependence on $\mathrm{T}_{\mathrm{s}}$ might be described by a complex function as

$$
\sigma\left(\mathrm{T}_{\mathrm{s}}\right)=\mathrm{f}\left\{\mathrm{P}\left(\mathrm{T}_{\mathrm{s}}\right), \mathrm{d}\left(\mathrm{T}_{\mathrm{s}}\right), \gamma\left(\mathrm{T}_{\mathrm{s}}\right)\right\} .
$$

Considering the effect of sintering temperature on structure and mechanical behavior of zirconia electrolytes as well as processes of powder consolidation and structure refinement at sintering as thermally activated, the relations installing dependencies between strength and grains and subgrains, porosity, quality of boundaries and sintering temperatures, as well as imaginary activation energies determining densification or porosity, grain size growth, boundary states and strengthening/weakening at cleavage or intergranular fracture mechanisms were determined.

The detailed analysis of the effect is given in [23].

As to the porosity $\mathrm{P}$ of $1 \mathrm{Ce} 10 \mathrm{ScSZ}$ ceramics, its dependencies on sintering temperature $T_{s}$ shown in Figure 2. It is obvious that they might be approximated by the Arrhenius's exponents as

$$
\mathrm{P}=\mathrm{P}_{\mathrm{o}} \cdot \exp \left(\mathrm{U}_{\mathrm{c}} / \mathrm{kT}_{\mathrm{s}}\right),
$$


where $U_{c}$ is the imaginary activation energy of densification.

It is seen that ability to densification is different in all the ceramics. The dependencies of porosity vs. sintering temperature are consisting of two parts: low- and high temperature ones. The transition between them occurs in withinity of $1400-1450{ }^{\circ} \mathrm{C}$. Each part (except of high temperature one in the Type II ceramics where the densification does not observe) has own the imaginary energy of activation, which are 0.35 and $0.78 \mathrm{eV}$ in the Type I ceramics, $1.4 \mathrm{eV}$ in the Type II ceramics sintered in its low-temperature stage, and 1.38 and $3.99 \mathrm{eV}$ in the Type III ceramics, respectively (Table 1).

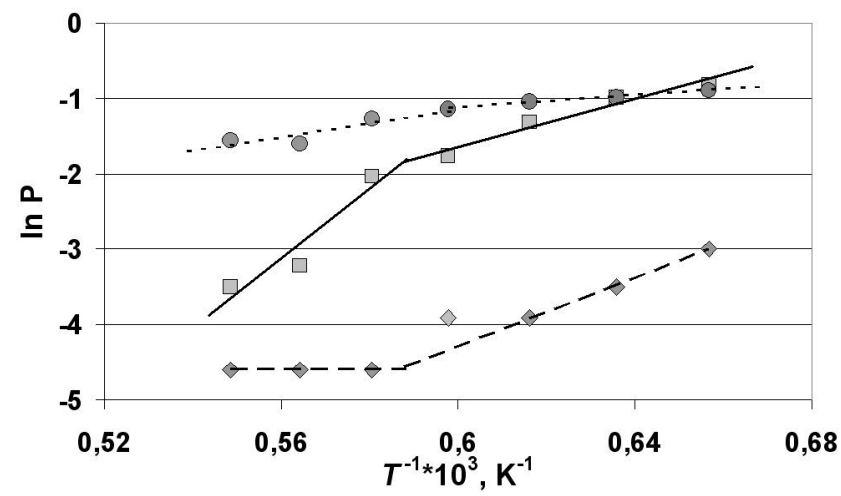

Figure 2. The Arrhenius's dependencies of porosity of $1 \mathrm{Ce} 10 \mathrm{ScSZ}$ ceramics made of three powder types on sintering temperature, Type I; Type II, and Type III [23].

Except very different ability to densification, the ceramics have the different ability to grain growth also. The Arrhenius's dependencies of the average grain size on sintering temperature are shown in Figure 3. It is seen that the dependencies might be described by exponents also, however, here, we have to note that the interval of sintering temperatures studied comprises both sintering stages, namely, the stage of a final sintering and the stage of an intraagglomerate consolidation. The transition from low- to high-temperature part takes place near $1400-1450{ }^{\circ} \mathrm{C}$ that is unexpectedly coinciding with data on temperature dependence of grain growth in structural tetragonal zirconia ceramics Y-TZP where tetragonal structure of zirconia is stabilized by 3 -mas. \% of yttria [37]. It is noted there that the transition from slow to fast grain growth occurs in withinity of $1400{ }^{\circ} \mathrm{C}$. This transition results in a practically double growth of the activation energy from 2.80 to 5.46 $\mathrm{eV}$.

The imaginary activation energies, $U_{g g}$, of grain size growth in $1 \mathrm{Ce} 10 \mathrm{ScSZ}$ ceramics is given in Table 1 . It is obvious that $\mathrm{U}_{\mathrm{gg}}$ is radically different for different sintering stages and depends strongly on the powder type also. At the final sintering stage, the imaginary energies of activation are $2.65,2.90$ and $4.21 \mathrm{eV}$ for the Type I, the Type II and the Type III electrolytes, respectively. For interagglomerate sintering, $\mathrm{U}_{\mathrm{gg}}$ is similar in ceramics of II and III Types, 0.96 and $1.01 \mathrm{eV}$ respectively.
Table 1. The imaginary energies of activation of densification $U_{c}$, and grain growth $\mathrm{U}_{\mathrm{gg}}$ of electrolyte ceramics sintered of three types of $1 \mathrm{Ce} 10 \mathrm{ScSC}$ ceramics at temperatures below and higher their inflection points $T_{0}[23]$.

\begin{tabular}{|c|c|c|c|c|}
\hline \multirow{2}{*}{$\begin{array}{c}\text { Powder } \\
\text { type }\end{array}$} & \multicolumn{4}{|c|}{ Imaginary activation energy, in average, eV } \\
\cline { 2 - 5 } & \multicolumn{2}{|c|}{$U_{c}$} & \multicolumn{2}{|c|}{$U_{g g}$} \\
\cline { 2 - 5 } & $<T_{o}$ & $>T_{o}$ & $<T_{o}$ & $>T_{o}$ \\
\hline I & 0.35 & 0.78 & - & 2.65 \\
\hline II & 1.4 & $\sim 0$ & 0.96 & 2.90 \\
\hline III & 1.38 & 3.99 & 1.01 & 4.21 \\
\hline
\end{tabular}



Figure 3. The Arrhenius's dependencies of average grain size of $1 \mathrm{Ce} 10 \mathrm{ScSZ}$ ceramics made of three powder types on sintering temperature, Type I; Type II, and Type III [23].

The dependence of the biaxial strength measured at room temperature on sintering temperature is shown in Arrhenius coordinates in Figure 4. Unlike dependencies of porosity and grain size, they are not similar. Furthermore, the Type II curve has a discontinuity at the inflection point in withinity $1375{ }^{\circ} \mathrm{C}$. I.e., the strength of each ceramic type on sintering temperature may be described by two exponents but their imaginary activation energies are so different, magnitude and sign, that in the case of the Type II ceramics we have to talk about weakening instead of strengthening. The imaginary energies of activation for strengthening / weakening, $\mathrm{U}_{\mathrm{s}}$, of three Types of $1 \mathrm{Ce} 10 \mathrm{ScSZ}$ ceramics is given in Table 1.

Fracture mechanisms and strength of $1 \mathrm{Ce} 10 \mathrm{ScSZ}$ electrolyte at room temperature are described in [20, 23].

Concerning the fractographical visualization of boundaries via their behavior under mechanical stresses at loading or their interaction with brittle cracks, it became possible to determine that they are brittle interpartial and intergranular (intergrain) fracture, and an alteration of cleavage plane and cracking at boundary crossing that could form so-called river patterns. 


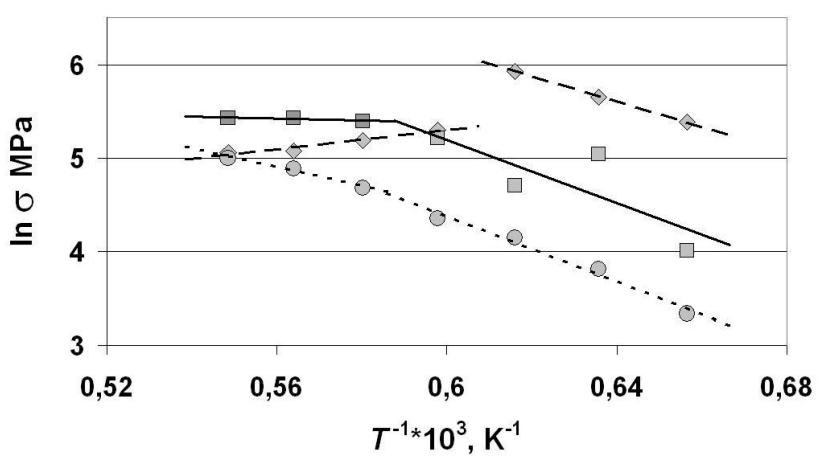

Figure 4. The Arrhenius's dependencies of room temperature biaxial strength of 1Ce10ScSZ ceramics made of three powder types on sintering temperature, Type I; Type II, and Type III [23].

This picture is altering with sintering temperature that results from the boundary complexion transitions that might be defined as the transition of the second kind that is, in fact, the transition between boundary complexions, between subgrain boundary and grain boundary ones. The first kind of the transition is the boundary complexion transition, which occurs within the same category of boundaries, e.g., intergranular one that is traditionally discussed. The second kind is the transition between categories of boundaries, e.g., from subgrain category to grain one. It may occur, i.e., at refinement of grains with a heat treatment removing impurities or unwanted structural elements from the grain. As result, the grains are refined from the subgrain boundaries, contaminations are redistributed within the grains or removed from them onto their boundaries. In such a way, the boundaries of subgrains disappear in much extent, and the grain boundaries remain in their new state. It may happen at some critical temperature interval. As a final result, material properties may alter at this temperature of heat treatment / sintering abruptly. The authors are succeeded in observing these phenomena relating fracture behavior, fracture mechanism especially, and electrical conductivity that will be shown below.

We have to note that the boundaries in the Type I ceramics do not reveal themselves in fractures practically at all with the microscopes available as it is possible to see in Fig. 5A, $5 \mathrm{~B}$. Though, the thermally etched surfaces of its samples evidence that some internal boundaries are there (Fig. 6A).

The Type II ceramics allow observing subgrains, which have been as initial particles before the sintering, and have united and created grains in a course of sintering. These grain creatures are well-visible already in samples sintered at $1250{ }^{\circ} \mathrm{C}$ for 1.5 hour (Fig. 5C-5E). The fractographical situation here is similar to that is observed at brittle fracture of deformed polycrystalline metals like Mo, W, Cr where two categories of boundaries may be observed simultaneously, namely boundaries of big initial grains and boundaries of small grains, which are as subgrains, which have arisen in material during plastic deformation. At $1300^{\circ} \mathrm{C}$, the Type II particles are consolidated already well enough (Fig. 5C). The sites of their joining, interparticle boundaries, are strong, stronger than of particle body; particles fail with the cleavage fracture mechanism mainly. Increasing sintering temperature only for $50{ }^{\circ} \mathrm{C}$, to $1350{ }^{\circ} \mathrm{C}$, results in dramatic increase of densification and new details in the fracture, so-called fragmentation that itself is fragmenting a large cleavage surface that is result of nanoand microcracking along boundaries of particles (Fig. 5D). Their joint effect is the maximal possible strengthening with particle boundaries that might be renamed as subgrain ones. The strength may reach above $400 \mathrm{MPa}$ (Figure 4). Thermally etched surfaces reveal two categories of structure: subgrains and grains, both of which are clearly distinguished in samples sintered at 1350 and $1450{ }^{\circ} \mathrm{C}$ (Fig. 6B-6C).

At sintering temperatures above $1350{ }^{\circ} \mathrm{C}$, the cracking resulted from an interaction of cleavage crack with the particle / subgrain boundaries is disappearing. We observe the typical picture of cleavage fracture of brittle polycrystalline material decorated by river patterns and crack slopes on each grain boundary (Fig. 5E). As result, the strengthening effect by boundaries decreases abruptly and strength drops to $\sim 200 \mathrm{MPa}$ at $1400^{\circ} \mathrm{C}$ (Figure 4). It is necessary to underline that material become slightly denser but significantly weaker because a number of strengthening elements decreases abnormally. Further increase of sintering temperature results in logical growing grain size and decreasing strength.

As to the Type III ceramics, their feature is that they fail with brittle interpartial and intergranular fractures mainly (Fig. 5F, 5H), and partially with cleavage in sintered at $1450^{\circ} \mathrm{C}$ samples (Fig. $5 \mathrm{G}$ ), in vicinity of which the transition from interpartial to intergranular fracture occurs where the strengths of particle bodies for cleavage and interpartial joining is probably equal. In vicinity of this transition temperature, that is near the inflection point on temperature dependence of grain size growth, its activation energy is altering from 1.01 to $4.21 \mathrm{eV}$ [23]. The grains and their subgrains are clearly visible on thermally etched surfaces of samples (Fig. 6D).

Thus, the Type III ceramics manifest the second kind of the complexion transition also, but the transition from particle boundaries to grain ones is complicated by that fact that it occurs in the material, subgrain boundaries of which is contaminated heavily by $\mathrm{SiO}_{2}$ and $\mathrm{TiO}_{2}$. And, if the complexion transition in the Type II ceramics occurs at a cleavage fracture mechanism mainly (Fig. 5C-5E), the transition in the Type III ceramics occurs at a fracture mechanism, the brittle crack of which is spreading along boundaries of particles at lower sintering temperatures and grains at higher temperatures (Fig. 5F, 5H). Only at temperature of the transition, that is around $1450^{\circ} \mathrm{C}$, samples fail with mixed mode - interpartial / intergranular and cleavage - manifesting that the strength of the particle / grain bulk and their boundaries are practically equal and the complexion transition of the second kind becomes possible (Fig. 5G). The porosity, which is developing along grain boundaries, is only facilitating the transition in spite of the comparatively high intergranular strength (Figure 4). 


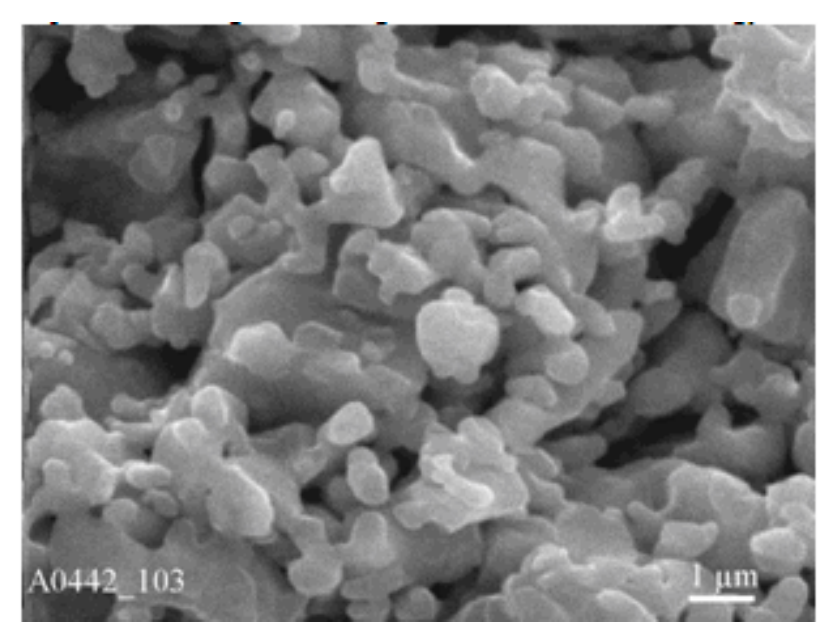

A

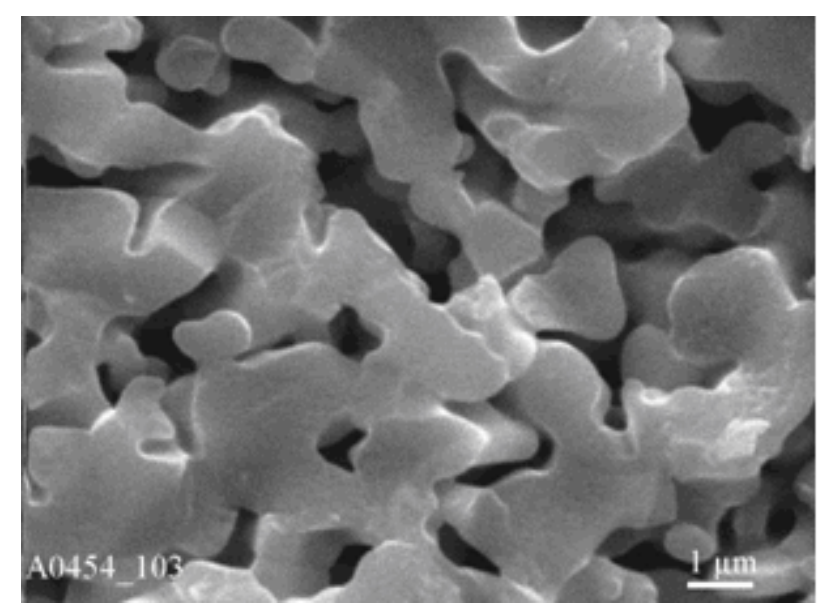

B

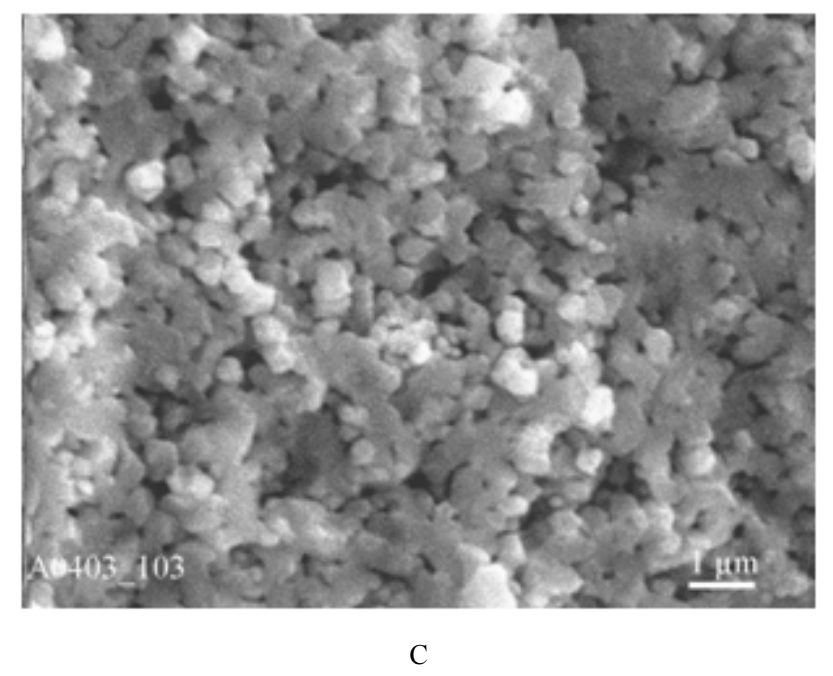

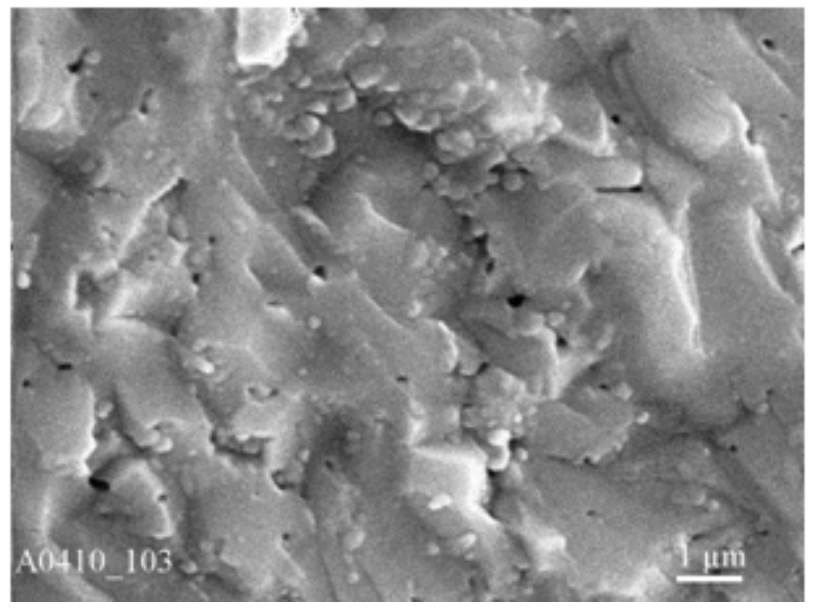

D

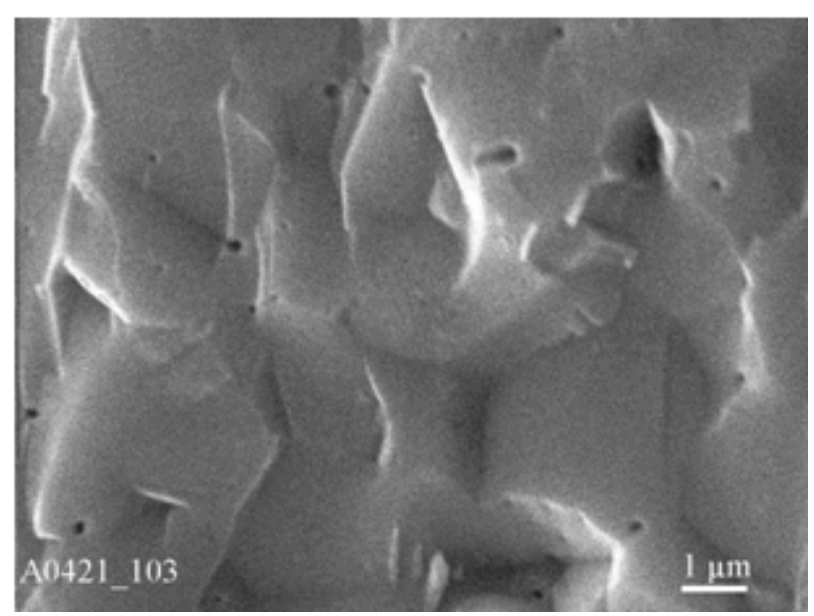

E

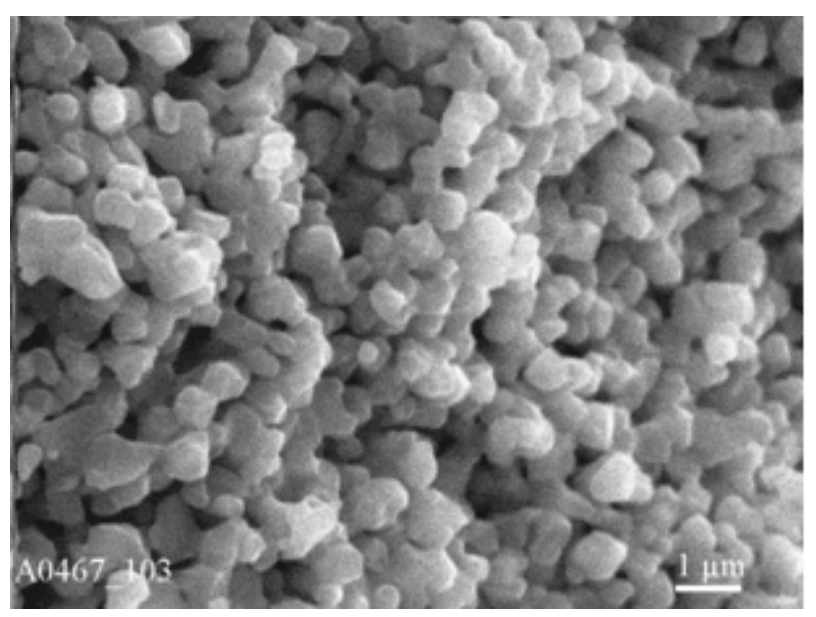

F 


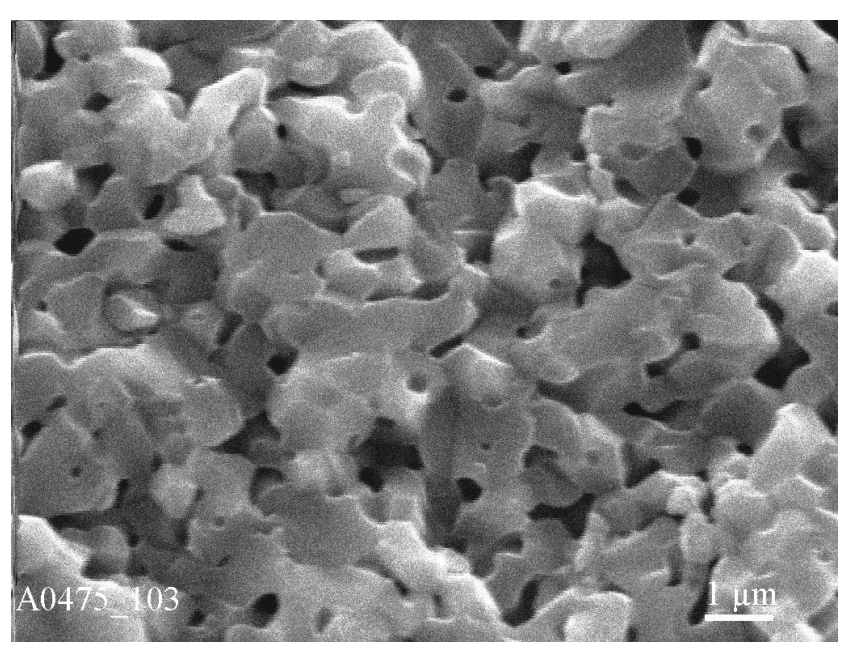

G

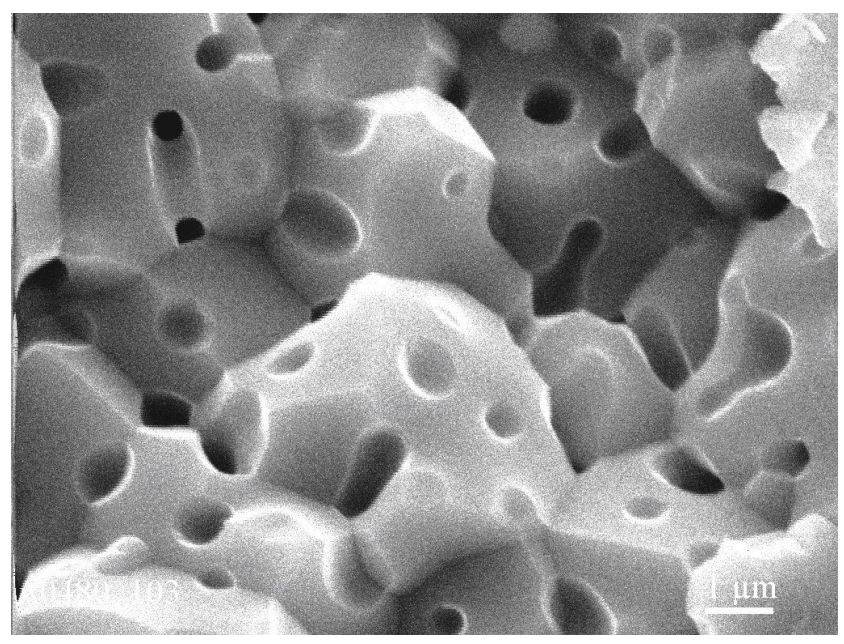

$\mathrm{H}$

Figure 5. SEM images of fracture surfaces of the electrolytes sintered of different powder types and at different temperatures: the Type I: A $1400{ }^{\circ} \mathrm{C} ; \mathrm{B}-1550{ }^{\circ} \mathrm{C}$; the Type II: $\mathrm{C}-1250{ }^{\circ} \mathrm{C}$; D $-1350{ }^{\circ} \mathrm{C}$; and $\mathrm{E}-$ $1550{ }^{\circ} \mathrm{C}$; the Type III: $\mathrm{F}-1350{ }^{\circ} \mathrm{C} ; \mathrm{G}-1450{ }^{\circ} \mathrm{C}$; and $\mathrm{H}-1550{ }^{\circ} \mathrm{C}[20,23$ etc.].

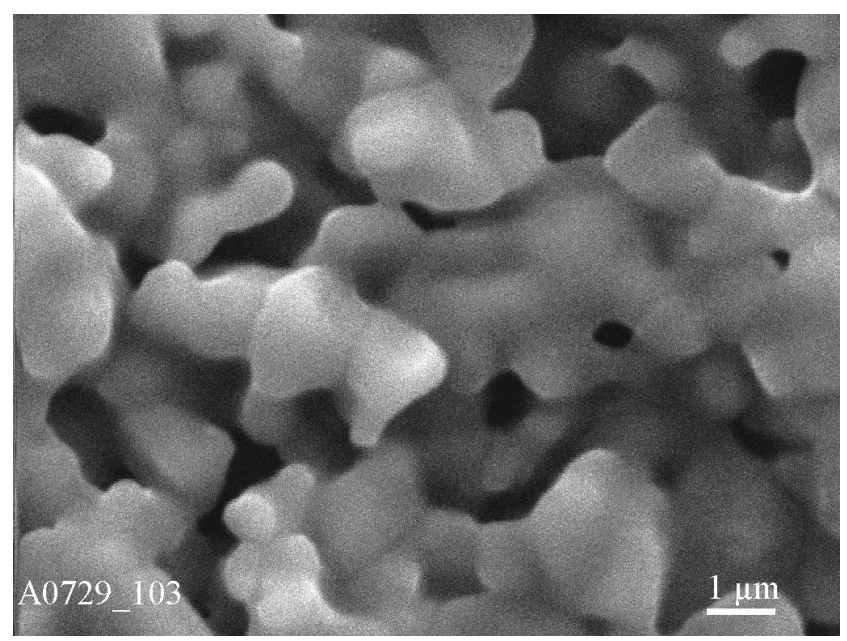

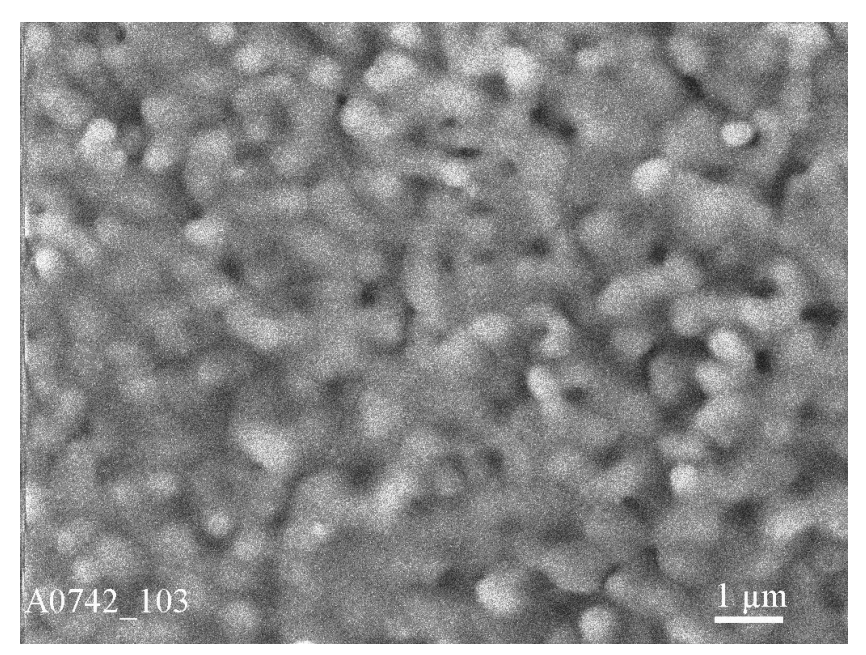

B

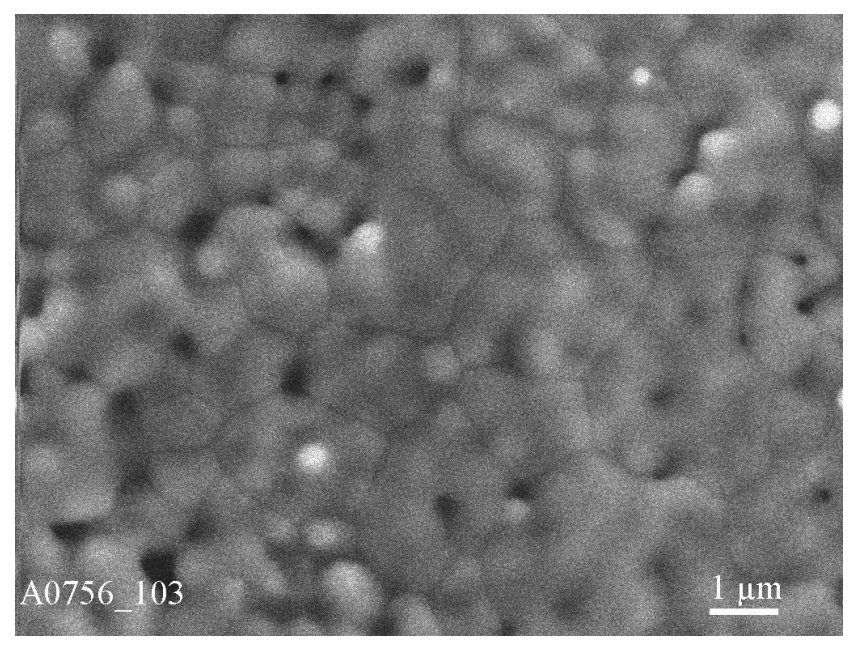

C

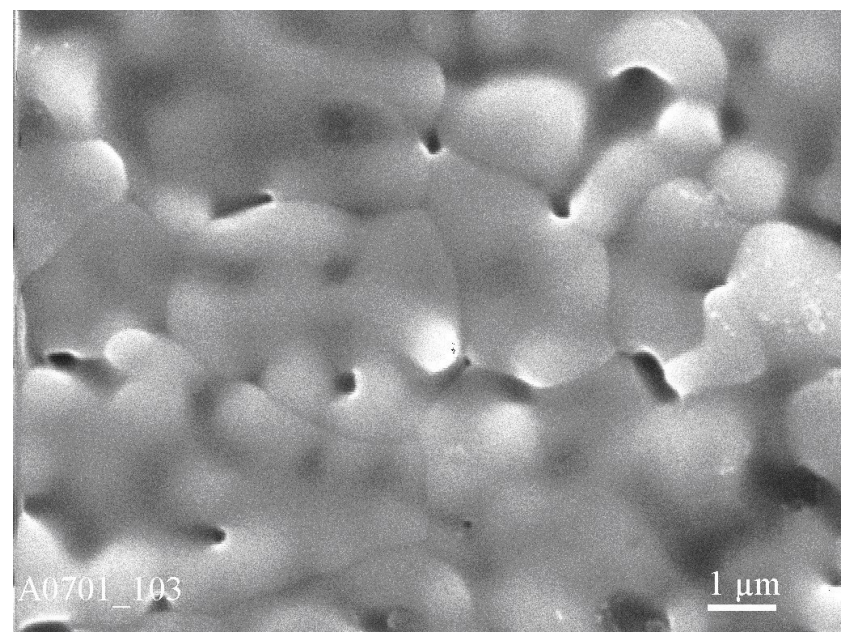

$\mathrm{D}$

Figure 6. SEM images of thermally etched surfaces of the electrolyte samples sintered of different powder types at different temperatures. The Type I: A $-1550{ }^{\circ} \mathrm{C}$; the Type II: $\mathrm{B}-1350{ }^{\circ} \mathrm{C} ; \mathrm{C}-1450{ }^{\circ} \mathrm{C}$; the Type III: $\mathrm{D}-1550^{\circ} \mathrm{C}$ 


\subsection{Electrical Conductivity of the Bulk Electrolyte}

The impedance spectroscopy allows distinguishing the contribution of each structural constituent into overall resistance of the material. It is traditionally applied for characterization of CFC materials. This non-destructive method is studying the system response to the application of a periodic small amplitude alternating current signal. These measurements are carried out at different frequencies. Analysis of the system response contains information about the boundaries, their structure and reactions taking place there.

The impedance spectroscopy data of ceramics obtained at the $600{ }^{\circ} \mathrm{C}$ test is given in [24] where the influence of the grain and subgrain boundaries on electrical conductivity of the $1 \mathrm{Ce} 10 \mathrm{ScSZ}$ electrolyte is considered. The required variety of the structural boundaries - subgranular and granular - are investigated for three types of the zirconia ceramics sintered at different temperatures and given below for each one separately.

\subsubsection{The Type I Ceramics}

As it was observed [24], the impedance spectra of the Type I samples have two or even three semicircles with the two intercepts on the real axis at higher frequencies corresponding to the total Ohmic and polarization resistances, respectively. The third semicircle in the low frequency range $(<1 \mathrm{~Hz})$ is due to the electrode effects and was observed only for the samples sintered at relatively low temperatures, $1250-1300{ }^{\circ} \mathrm{C}$ that had low mechanical strength and were highly porous leading to high Ohmic resistances. The second intercept at the intermediate frequencies of $50-100 \mathrm{~Hz}$ is related to the blocking of charge carries due to the internal surfaces of the specimens also denoted as intergranular response (grain boundary). The first semicircle at high frequencies (with the peak frequency of $200-398 \mathrm{kHz}$ was assigned to the bulk (intragranular) response (grain) and the intercept on the real axis in the high frequency range represented the total Ohmic resistance.

The grain boundary resistance of the Type I samples is about $30 \Omega \cdot \mathrm{cm}$ (Fig. 7A) that does not depend on the sintering temperature. The porosity of the samples decreases from 37 to $21 \%$ with increasing sintering temperature from 1300 to $1550{ }^{\circ} \mathrm{C}$, causing increase in the electrical conductivity of the samples. The results of the secondary ion mass spectroscopy showed [20] that the surface layer of Type I particles has a large amount of contaminants $-\mathrm{Al}^{3+}, \mathrm{Si}^{4+}$ and $\mathrm{K}^{+}$, which are known as elements decreasing the ionic conductivity. The grain resistance of the Type I samples is equal to $14 \Omega \cdot \mathrm{cm}$ and 9.5 $\Omega \cdot \mathrm{cm}$ at 1300 and $1350{ }^{\circ} \mathrm{C}$ sintering temperatures, respectively, and further temperature increase to $1400-1500{ }^{\circ} \mathrm{C}$ decreases it to $\sim 5 \Omega \cdot \mathrm{cm}$.

\subsubsection{The Type II Ceramics}

The Type II 10Sc1CeSZ samples have only one semicircle indicating the grain boundary resistance in the frequency range of 50-79 $\mathrm{Hz}$ [24]. They have the highest total ionic conductivity due to near zero grain resistance. The grain boundary resistance of the samples obtained at $1300-1350^{\circ} \mathrm{C}$ is about $30 \Omega \cdot \mathrm{cm}$, slightly decreases at $1400^{\circ} \mathrm{C}$, and drops twice as much at $1450-1500{ }^{\circ} \mathrm{C}$ (Fig. 7B).

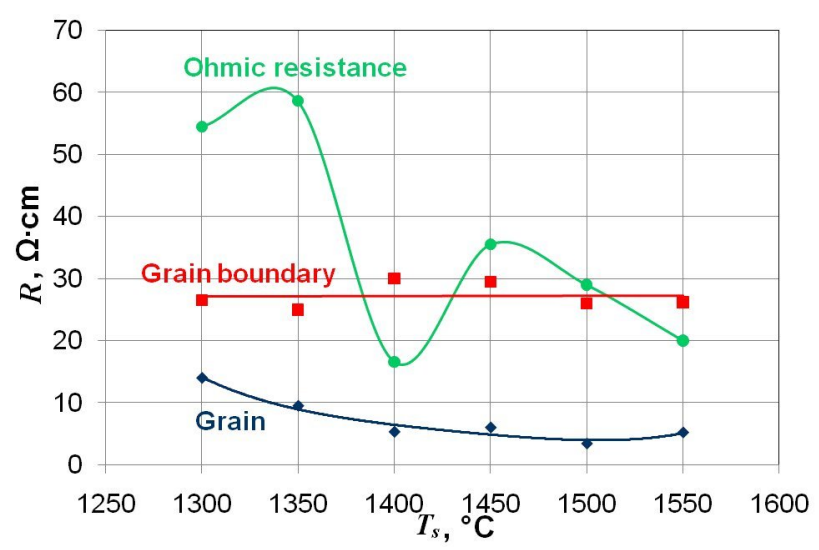

A

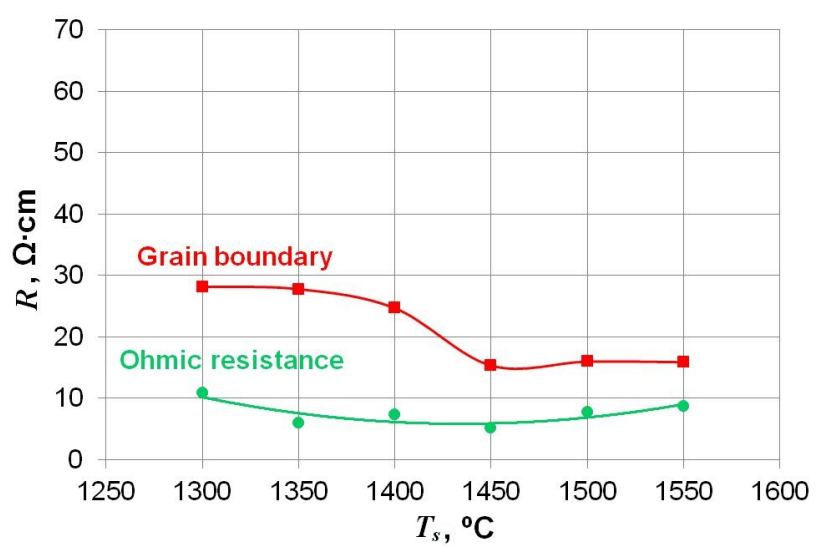

B



C

Figure 7. Grain, grain boundary and Ohmic resistances of the Type I (A), the Type II (B), and the Type III (C) samples vs. sintering temperature. Dots - experimental data, lines - model approximation [24].

The Ohmic resistance of these samples show a parabolic behavior: it decreases from $11 \Omega \cdot \mathrm{cm}$ at $1300{ }^{\circ} \mathrm{C}$ to $\sim 6 \Omega \cdot \mathrm{cm}$ 
at the intermediate sintering temperatures and then increases again to the initial values at sintering temperature of $1550{ }^{\circ} \mathrm{C}$. As result of the high purity of the Type II powder $\left(<10^{-3} \mathrm{wt}\right.$. $\%$ of impurities $)$ a considerable grain growth during the sintering process is observed. Such behavior can be explained by the weak influence of the initial boundaries of the particles (subgrains) on a grain recrystallization during the sintering process. Due to this, identification of the grain edges (subgrains) is very complicated and the structure fragmentation totally disappears at the sintering temperatures above $1400{ }^{\circ} \mathrm{C}$. We assume, that the absence of the grain response (explained by the extremely low impurities content and the decrease of the grain boundary resistance of the samples sintered at the temperatures above $1450{ }^{\circ} \mathrm{C}$ ) is determined by the grain boundaries improvement, for instance, homogenization of the impurities and structural changes of the grain boundaries.

\subsubsection{The Type III Ceramics}

As it is shown in Fig. 7C, the Type III samples sintered at 1300-1400 ${ }^{\circ} \mathrm{C}$ and $1550{ }^{\circ} \mathrm{C}$ have two semicircles responsible for the grain boundary $(63-316 \mathrm{~Hz})$ and the grain bulk (316-794 Hz) resistances. All other Type III samples demonstrate only one semicircle related to the grain boundary response $(126-158 \mathrm{~Hz})$. Here, the grain boundary resistance $(30 \Omega \cdot \mathrm{cm})$ is similar to the Type I ceramics and is independent on the sintering temperature. However, taking into account significant densification and porosity decreases from $37 \%$ at $\mathrm{T}_{\text {sint }}=1300{ }^{\circ} \mathrm{C}$ to $\sim 0 \%$ at $\mathrm{T}_{\text {sint }}=1550{ }^{\circ} \mathrm{C}$, the grain boundary resistance is increasing. This can be explained by the electrical conductivity decrease relevant to the $\mathrm{Al}^{3+}, \mathrm{Si}^{4+}$, and $\mathrm{K}^{+}$doping ions found on particle surfaces in this and Type I powders at the first stage of sintering, and the porosity localization along grain boundaries at the second sintering stage. The grain bulk and the Ohmic resistances of the ceramics are decreasing with increasing sintering temperatures up to $1450-1500{ }^{\circ} \mathrm{C}$, however, they are increasing at $\mathrm{T}_{\text {sint }}=1550$ ${ }^{\circ} \mathrm{C}$. Unlike Type I, the Type III powder consists of chips-like agglomerates that together with interpartial admixtures $\left(\mathrm{TiO}_{2}, \mathrm{SiO}_{2}\right)$ accelerate the sintering. An improved contact between the grains at $\mathrm{T}_{\text {sint }}=1450-1500{ }^{\circ} \mathrm{C}$ decreases the grain bulk and the Ohmic resistances ( 0 and $15 \Omega \cdot \mathrm{cm})$, respectively. The increase of the grain bulk resistance to $13.5 \Omega \cdot \mathrm{cm}$ and Ohmic resistance to $20.2 \Omega \cdot \mathrm{cm}$ at $\mathrm{T}_{\text {sint }}=1550{ }^{\circ} \mathrm{C}$ is related to the intragranular porosity increase.

Comparing data on the electrical response, it was unexpected, that the electrical resistance responsible for boundaries in the samples made of all three powders sintered at temperatures up $1300-1400{ }^{\circ} \mathrm{C}$ is practically the same and equal to $\sim 30 \Omega \cdot \mathrm{cm}$. Only at further increase of sintering temperature, the changes of an intergranular resistance related to the sintering temperature are observed.

In pure the Type II material, the grain boundary resistance drops abruptly by half. The relevant changes are observed in mechanical strength that drops abruptly by more than half. The nanocracks related to subgrain boundaries disappear as relevant fractographical mark of the interaction between the cleavage cracks and the subgranular boundaries (Figs. 5C-5E). These complex properties may indicate that in the Type II electrolyte, the sintering at $1350-1400{ }^{\circ} \mathrm{C}$ results in a full dissolution of initial particle boundaries, which play a role of subgrain boundaries and are observed as a fractographical fragmentation of grains fracture with cleavage (Fig. 5D) and high subgrain boundary resistance (Fig. 7B).

The data on the impedance spectroscopy and mechanical behavior (SEM fractography and strength) also indicate two different stages of the traditionally determined boundary or intergranular resistance. During the first stage, till the $1300-1400{ }^{\circ} \mathrm{C}$ critical temperatures, the boundary resistance in $10 \mathrm{Sc} 1 \mathrm{CeSZ}$ is $\sim 30 \Omega \cdot \mathrm{cm}$ that is independent on contaminants and other properties of powders used for the electrolyte production. The improvement of interpartial or subgranular boundaries is reflected in a rapid growth of the electrolyte strength to more than $400 \mathrm{MPa}$ at biaxial bend. High electrical resistance $(\sim 30 \Omega \cdot \mathrm{cm})$ of these boundaries points out a weak influence on temperature at this stage of sintering.

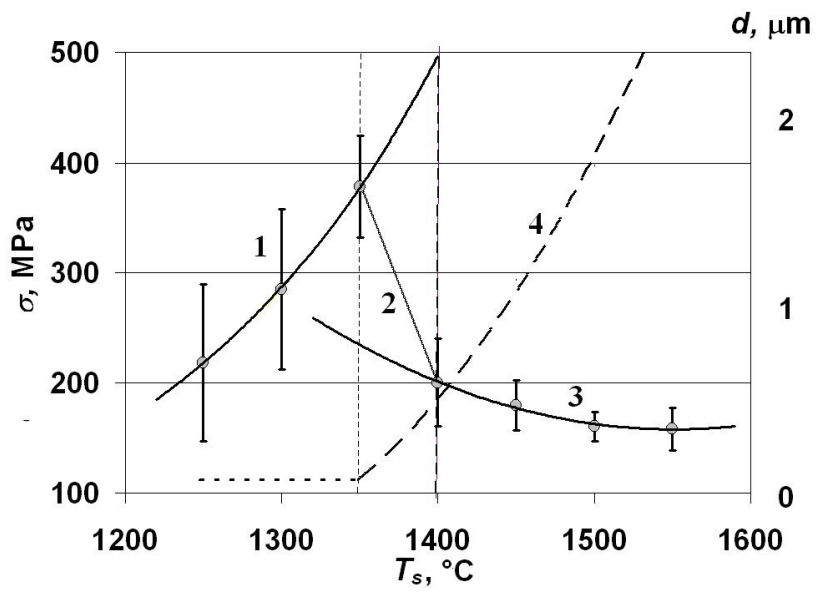

Figure 8. The generalized schematic representation of a Type II ceramics strengthening-weakening with sintering temperature that results from relative structural element altering. 1 - subgrain strengthening, 2 transition from subgrain strengthening to grain weakening, 3 - grain growth weakening, 4 - size of effective structural element [23].

Considering an influence of sintering temperature on the structural parameters and mechanical behavior of $10 \mathrm{Sc} 1 \mathrm{CeSZ}$ electrolyte we might conclude [23] that the sintering temperature of $1300-1400{ }^{\circ} \mathrm{C}$ is critical for the Type II material. Namely at this temperatures, the activation energies of grain growth and densification, strengthening or weakening occur. Namely in vicinity of $1300-1400{ }^{\circ} \mathrm{C}$, the strength of the Type II electrolyte is decreased abruptly that is a result of replacement of basic strengthening constituent of the material when subgrains, which boundaries were improved with increasing temperature up to $\sim 1375^{\circ} \mathrm{C}$ and dissolved with a further increasing temperature to $\sim 1400{ }^{\circ} \mathrm{C}$, are replaced abruptly by grains. It should be emphasized 
here that the grain size does not reveal any evident deviations from the exponential growth that might cause such dramatic changes of the mechanical strength and its decrease from more than 400 to $150 \mathrm{MPa}$. Schematically, the results of the contradictory processes are shown in Figure 8, where the transition between strengthening elements and their sizes are given also. The reader is asked to compare Figs. 8 and 7B.

During the second stage, at temperatures above $1300-1400{ }^{\circ} \mathrm{C}$, the situation is changed radically. Here, the grains, the boundary structure of which became rather perfect in order to be easy distinguished fractografically via as both disorientation like in pure the Type II electrolyte and admixture segregation additionally like in Types I and III electrolytes. The intergranular constituent of the resistance may be decreased with both abrupt decrease of a specific boundary surface like it happens in Type II electrolyte, and promoting chemical composition of a small amount of impurities segregating along grain boundaries.

In ceramic electrolytes containing a large number of contaminants, the grain boundary response has an unexpected behavior. The temperature increase and the adequate growth of the grain size that depends on amount of admixtures, which are either constraining grain growth like in the Type I electrolyte, or promoting grain growth like in the Type III electrolyte, do not reflect measurably in neither increase, neither decrease of the grain boundary resistance in spite of the influence significantly on the mechanical behavior. At the level of $30 \Omega \cdot \mathrm{cm}$, the difference in neither chemical composition of admixtures and their amounts, nor in their distribution across structure of initial powder particles.

It is known that a deviation from the Debye's model indicates a greater degree of structural heterogeneity [24]. The application of the Havriliak-Negami model [38] to the single semicircle may be as an evidence of continuous solid microstructure, where the grain and grain boundary phases cannot be distinguished, i.e., both the bulk of the grains and the intergranular layers have the same chemical composition that may explain the existence of the only one semicircle in a complex plane of Type II $10 \mathrm{Sc} 1 \mathrm{CeSZ}$ electrolyte impedance. Thus, the solid phase of the Type II electrolyte is as single-phase in contrast to the Types I and III where there is the grain bulk and the phase of the intergranular layers of different origins.

In such a way, the heat treatment, determined by temperature and time, via sintering and the powder typification are the suitable and convenient thermodynamical and chemical tools for the boundary engineering with "useful or non-useful" admixtures to control the boundary complexions and their transitions in sintered materials such as stabilized zirconia electrolyte. Using this approach, the most full variety of structural parameters such as porosity, subgrain and grain size growth and redistribution of admixtures across structural constituents and their boundaries, and altering their states have become available for the study. Joint analysis of data obtained with electron microscopy and related techniques, mechanical tests for strength, scanning electron fractography and impedance spectroscopy of structural constituents of electrical resistance is giving much more reliable information on the effect of boundaries and their complexions on properties of materials especially such as ceramic electrolytes where mechanical behavior is as important as their conductivity.

In the electrolyte made of three types of $1 \mathrm{Ce} 10 \mathrm{ScSZ}$ powder, two kinds of boundary complexions, subgranular and granular, were observed. They are developing in both very pure and of technical purity materials with sintering temperature. Moreover, the transitions between complexions, those might be defined as the boundary complexion of the second kind, occur. The transition results in dramatic altering of electrolyte properties.

The first kind of the boundary complexion transition means usually the transition within the same category of boundaries, e.g., of subgrains or their grains. The second one is the transition between categories, e.g., from subgrains to their grains when the mechanical behavior and the boundary resistance become to be determined by grain boundaries, of course, jointly with the grain bulks.

The second kind of the boundary complexion transition caused by sintering in temperature interval $1250-1550{ }^{\circ} \mathrm{C}$ occurs in both very pure $1 \mathrm{Ce} 10 \mathrm{ScSZ}$ ceramics (the Type II), boundaries of which are contaminated with small amounts of $\mathrm{Sc}$ and $\mathrm{Al}$, and in $1 \mathrm{Ce} 10 \mathrm{ScSZ}$ of technical purity (the Type III), powder of which is contaminated with large amounts of silica $(0.05 \%)$ and titania $(<0.14 \%)$.

The Type I ceramics made of powder contaminated with silica $(0.05 \%)$ and alumina $(<0.025 \%)$ does not reveal any notable changes in properties those might be related to the boundary complexion transitions in the temperature interval of the sintering studied. The Type I ceramics does not reveal nor fracture mechanism change (it fails with cleavage only), nor boundary resistance change. The dependence of the grain size on sintering temperature of the Type I ceramics in Arrhenius coordinates has the inflection at $\sim 1450^{\circ} \mathrm{C}$.

The boundary complexion transition in the Type II ceramics reveals itself as the transition from subgrain strengthening to grain weakening, which manifests the abrupt drop of strength resulting from any interaction of cracks with intragranular (subgrain) boundaries accompanied by cleaning the cleavage picture from any marks of cracking at boundaries. It occurs in samples sintered in the narrow temperature interval $1350-1400{ }^{\circ} \mathrm{C}$ where the dependence of the grain size on sintering temperature in Arrhenius coordinates has the inflection.

The boundary complexion transition in the Type III ceramics reveals itself as the transition from the brittle interpartial fracture to the brittle intergranular one except a mixed with cleavage intergranular fracture at temperature $1450{ }^{\circ} \mathrm{C}$ where the dependence of the grain size on sintering temperature in Arrhenius coordinates has the inflection too.

The impedance spectroscopy study confirms also that the 
$1 \mathrm{Ce} 10 \mathrm{ScSZ}$ electrolyte is largely heterogeneous, and its degree of heterogeneity is determined by not only the type of the powder, but its sintering temperature. In many cases, the electrical resistance of the polycrystalline electrolyte samples is determined by the grain bulk and their intergranular layers. In some cases, like in the Type II electrolyte, the polycrystalline electrolyte exists as a single phase one where ionic conductivities of grain bulk and their boundaries are similar. This results in the electrical response with the only one semicircle characterizing the resistance of the boundary complexion.

It is surprising that the resistance of intergranular phase is near $30 \Omega \cdot \mathrm{cm}$ in all samples made of very different the Type I and Type III powders sintered at all temperatures studied, and does not depend on the type and the amount of admixtures (either $\mathrm{SiO}_{2}$ and $\mathrm{Al}_{2} \mathrm{O}_{3}$ in the Type I, either $\mathrm{SiO}_{2}$ and $\mathrm{TiO}_{2}$ in the Type III, either the third oxides (the total number of $\mathrm{Si}, \mathrm{Al}, \mathrm{Ti}, \mathrm{Fe}$ oxides is $\sim 0.01 \%$ ) in the Type II at sintering temperatures below $\sim 1375{ }^{\circ} \mathrm{C}$ ) and their distribution across the grains, grain size and general porosity.

Only in the Type II electrolyte sintered at temperatures above $\sim 1375^{\circ} \mathrm{C}$, the boundary resistance is abruptly decreasing from $\sim 30$ to $17 \Omega \cdot \mathrm{cm}$. Namely, in withinity of this temperature, the activation energy of numerous thermoactivated processes of powder consolidation is changed, the grain bulk is purifying from the subgrain boundaries as the fractography evidences. The mechanical strength decreases here abruptly from $400 \mathrm{MPa}$ to $150 \mathrm{MPa}$ as result of abrupt replacement of the effective strengthening structural element from subgrain for grain and, thereby, abrupt decrease of their number.

As to the grain bulk resistance, it can be concluded that in the Type I electrolyte, it decreases continuously from 14 to $6 \Omega \cdot \mathrm{cm}$ with porosity decrease at $1300-1450{ }^{\circ} \mathrm{C}$ and does not depend on structural evolution considering the cleavage fracture mechanism that may evidence continuous altering in the grain bulks and their boundaries with no any transitions, at least at temperatures in the interval studied. In the Type II electrolyte, the grain body resistance cannot be detected indicating that the electrochemical properties of the grain bodies and their boundaries are the same, and the material looks like a single phase one. In the Type III electrolyte, the resistance decreases from 20 to $5 \Omega \cdot \mathrm{cm}$ at decreasing porosity and interpartial fracture mechanism at $1300-1400{ }^{\circ} \mathrm{C}$; it becomes almost zero at mixed fracture mechanisms containing intragranular cleavage $\left(1450-1500^{\circ} \mathrm{C}\right)$, and increases to $13 \Omega \cdot \mathrm{cm}$ during the recrystallizing grain growth.

\subsection{Structure and Properties of EB-PVD Electrolyte Film}

EB-PVD is a promising process that might enhance the electrochemical performance of CFC. EB-PVD deposited thin layers contribute to the $\mathrm{CFC}$ lifetime increase and their cost reduction. CFC based on $1 \mathrm{Ce} 10 \mathrm{ScSZ}$ electrolyte deposited by EB-PVD has demonstrated an area specific resistance of $\sim 0.6 \mathrm{ohm} \cdot \mathrm{cm}^{2}$ at $600{ }^{\circ} \mathrm{C}$ and a He leakage rate below $10^{-4} \mathrm{mbar} \cdot 1 \cdot \mathrm{cm}^{-2} \cdot \mathrm{s}^{-1}[28]$. The conductivity of EB-PVD deposited films on a NiO-8YSZ anode is $\sim 50 \%$ higher than that of layers made with traditional SOFC technology [19]. The data were obtained at once with no any optimization.

This high performance is the result of a combination of 1Ce10ScSZ powder, ensuring high electrolyte conductivity, and the electron beam technique, ensuring dense unidirectional nano-sized structure on highly porous NiO-8YSZ anode substrate. Additionally, a strong adhesion of the EB-PVD electrolyte to the porous anode is achieved, which in itself is a very important prerequisite for high quality SOFCs. The EB-PVD films consist of columns (nanosized diameters and microsized length) and microlamellae; they have a cubic crystalline structure. In addition, the films made of $1 \mathrm{Ce} 10 \mathrm{ScSZ}$ powders are doped with $\mathrm{Ni}$ and $\mathrm{Y}$ due to an interdiffusion of dopants between the anode substrate and the deposited EB-PVD film. The Ni content at the anode - electrolyte interface (AEI) can exceed 2 -wt. \% that may decrease its conductivity significantly in a course of CFC operation. An area of EB-PVD film bordering AEI has higher the elasticity modulus than average [29].

However, one problem that has yet to be solved is the comparatively high gas leakage through zirconia films deposited on porous $\mathrm{NiO}-\mathrm{ZrO}_{2}$ substrates. This requires both further elaborations of comparatively thick films deposited on highly porous two-phase substrates and comprehensive structural characterization of EB-PVD films. This not only refers to the bulk of a film, but mainly to its interface with the heterogeneous substrate.

\subsubsection{Structure revealed at a micron level}

A polished cross-section of the transitional zone between the electrolyte film and its $\mathrm{NiO}-\mathrm{ZrO}_{2}$ substrate shows that the EB-PVD film has a columnar and laminar structure that is invisible in fracture (Figures 9 and 10).

The porous substrate is well covered by film in spite of its rather big pores. With respect to structural features, columns and filaments, nano- and microlaminae, cracks between filaments and groups thereof and pores can be discerned. The interface line is discontinuous; it is interrupted by pores as it is seen in areas highlighted by the white ellipses. Some less structured layer with a lighter color can be distinguished in the electrolyte zone nearest to the anode.

Figure 10 displays the SEM image of a fracture cross-section of a $\sim 65 \mu \mathrm{m}$ thick film that has been fractured in a bi-axial bending test. As it is seen, the electrolyte film has a well-defined columnar nano-structure and has failed at the transcolumnar cleavage with some intercolumnar fracture that implies rather high adhesion between the columns.

It is remarkable, that the transition from porous to visibly non-porous state occurs at a film thickness of 2 to $3 \mu \mathrm{m}$. It says that a thickness of the leakage proof EB-PVD film on porous Ni- $\mathrm{ZrO}_{2}$ anode could be less $5 \mu$. 


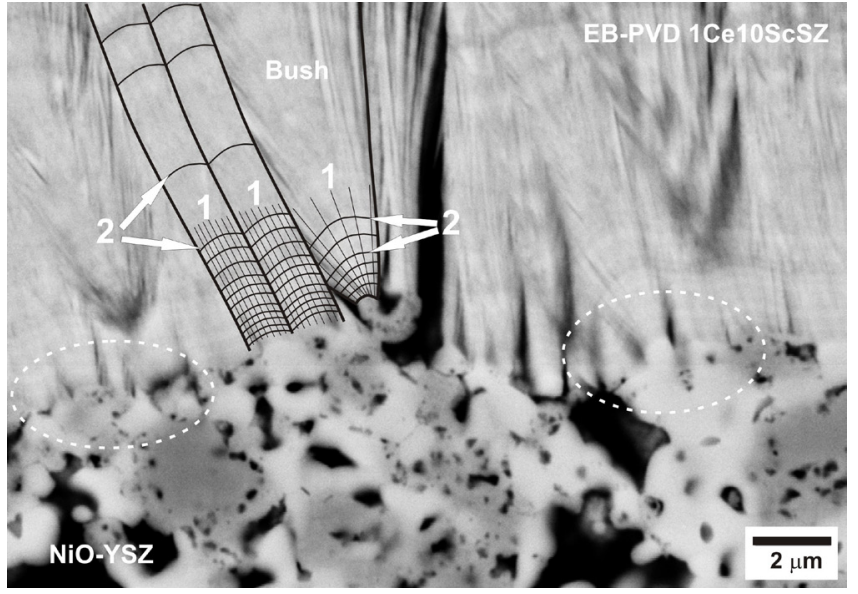

Figure 9. SEM (back scattered electron) image of polished cross-section of the anode-electrolyte interface zone. In the anode part, white areas are $\mathrm{ZrO} 2$ (1Ce10ScSZ) phase; light grey ones are NiO phase; black areas are pores. In the electrolyte part, filaments (1), bushes of filaments and nanoand microlaminae (2) are clearly recognized. Black areas are interfilament cracks and pores. A lighter stripe bordering the NiO-YSZ composite can be clearly discerned. Ellipses highlight areas with interface discontinuities resulting from the nucleation in groupings of cell/filaments (bushes) [29].

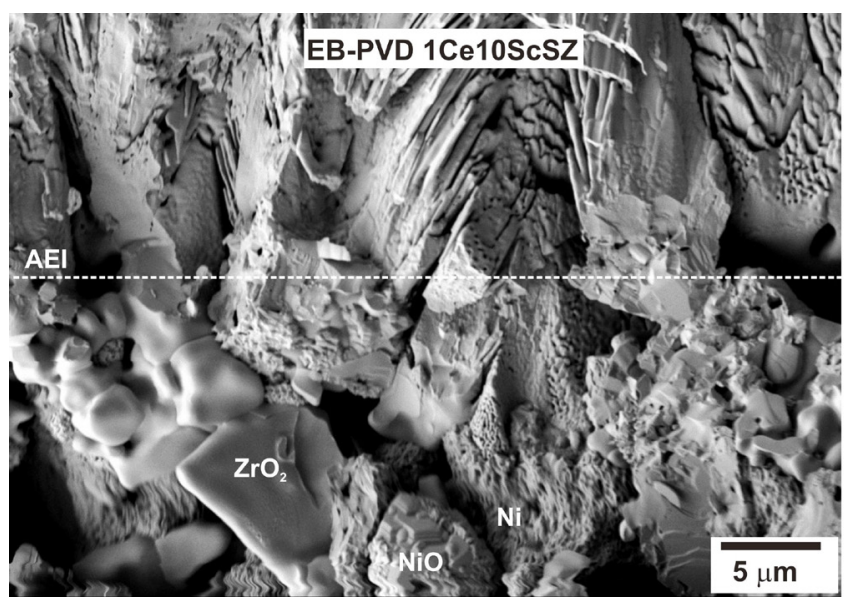

Figure 10. SEM image of the anode-electrolyte interface zone revealed in a fracture cross-section of the NiO-8YSZ anode substrate - 1Ce10ScSZ EB-PVD electrolyte film [29].

It can also be seen that the porous structure of the anode is well covered by the electrolyte layer. There are no visible delamination cracks along the interface between the film and its $\mathrm{NiO}-8 \mathrm{YSZ}$ substrate that might eventually lead to CFC failure. The EB-PVD film has no visible porosity. It can be seen also that the EB-PVD electrolyte film on the porous NiO-8YSZ substrate grows like bushes consisting of long branches, which have nano-sized diameter.

\subsubsection{Structure revealed at a submicron level}

The structure of the AEI area of the $1 \mathrm{Ce} 10 \mathrm{ScSZ}$ film formed on $8 \mathrm{YSZ}$ grains of the anode $\left(\mathrm{ZrO}_{2}-\mathrm{ZrO}_{2} \mathrm{AEI}\right)$ after annealing at $1100{ }^{\circ} \mathrm{C}$ is shown in Figs $11 \mathrm{~A}-11 \mathrm{~B}$. It is seen that zirconia grain of the substrate is covered by a continuous, smooth, porous layer of $300-500 \mathrm{~nm}$ thickness, which has no any other visible structure. This layer is covered by columns or filaments those are almost perpendicular to the
AEI along all the visible $(\sim 7-8 \mu \mathrm{m})$ part.

The deposited columns / filaments surround the supporting 8YSZ grain like petals of daisy or sunflower. Schematically, the structure of $1 \mathrm{Ce} 10 \mathrm{ScSZ}$ film on the $8 \mathrm{YSZ}$ substrate deposited with EB-PVD is sketched in Fig. 12A.

The porosity of the $1 \mathrm{Ce} 10 \mathrm{ScSZ}$ layer is high and has no any visible order. The size of pores displays a large scatter of values in the 10-60 $\mathrm{nm}$ range.

The line of the $1 \mathrm{Ce} 10 \mathrm{ScSZ}-8 \mathrm{YSZ}$ AEI looks smoothly curved; it consists of an uniform chain of pores of around 10 $\mathrm{nm}$ size, which makes the AEI easy visible. It is possible to assume that the electrolyte layer was amorphous and very defective initially and the facetted pores in the layer have arisen during annealing.

The investigated columns / filaments have about 100 to $300 \mathrm{~nm}$ diameters. They are separated by discontinuous, longitudinal interfilament flaws of 100-200 nm width and a few $\mu \mathrm{m}$ lengths.

With respect to the $1 \mathrm{Ce} 10 \mathrm{ScSZ}-\mathrm{NiO}$ part of the AEI, the structural features are somewhat more complicated as it is seen in Figs 11B. In contrast to the $1 \mathrm{Ce} 10 \mathrm{ScSZ}-8 \mathrm{YSZ}$ AEI, the $1 \mathrm{Ce} 10 \mathrm{ScSZ}-\mathrm{NiO} \mathrm{AEI}$ is not smooth. Moreover, it is discontinuous and stepped. Its discrete parts or island are dense, monocrystalline or polycrystalline (Figure 13).

Fig. 11B displays a few zirconia (1Ce10ScSZ) dendrites, or bushes of columns / filaments, which have nucleated on a $\mathrm{NiO}$ grain along $\sim 3.5 \mu \mathrm{m}$ of its boundary length. In contrast to the $1 \mathrm{Ce} 10 \mathrm{ScSZ}-8 \mathrm{YSZ} \mathrm{AEI}$, the zirconia dendrites have nucleated here on some preferable crystallographic planes like trees on a hill terrace. Zirconia dendrites seem to nucleate and grow on the $\mathrm{NiO}$ substrate in one direction, probably [100]. In full analogy with bushes or trees, a trunk, branches / filaments, and even some $1 \mathrm{Ce} 10 \mathrm{ScSZ}$ root in the $\mathrm{NiO}$ substrate may be distinguished. Moreover, the zirconia trunks seem to ingrow into the $\mathrm{NiO}$ grain. The nucleation on preferable crystallographic planes makes the $1 \mathrm{Ce} 10 \mathrm{ScSZ}-$ $\mathrm{NiO}$ AEI line as discontinuous and terraced. The area bordering to the AEI on the $\mathrm{NiO}$ side has a different contrast than the rest of the $\mathrm{NiO}$ grain, and contains a few dislocations. The thickness of this area is around $0.5 \mu \mathrm{m}$. It might be stated that the $1 \mathrm{Ce} 10 \mathrm{ScSZ}$-tree was ingrowing into the modified part of the $\mathrm{NiO}$ grain. Some $1 \mathrm{Ce} 10 \mathrm{ScSZ}$-trunks look as monocrystalline; other trunks are polycrystalline, containing well-visible facetted grains of $\sim 100-300 \mathrm{~nm}$ size. Pores between trunks along the line of their AEI as well as other pores and cracks located between trunks and their upper branch / filaments are observed. Some underdeveloped nucleus is observed also on the surface of the $\mathrm{NiO}$ grain inside the large pore between two 1 Ce10ScSZ trunks. The height of trunks to their branching site is roughly around $0.5-0.7 \mu \mathrm{m}$. It is interesting that similar to usual trees, the trunks of $\mathrm{ZrO}_{2}$-trees have also some well-visible thickening near the $\mathrm{NiO}$ "ground", i.e. at their very base.

Schematically, the processes of nucleation and growth of $\mathrm{ZrO}_{2}$ film on the NiO substrate at the EB-PVD process are sketched in Fig. 12B. 


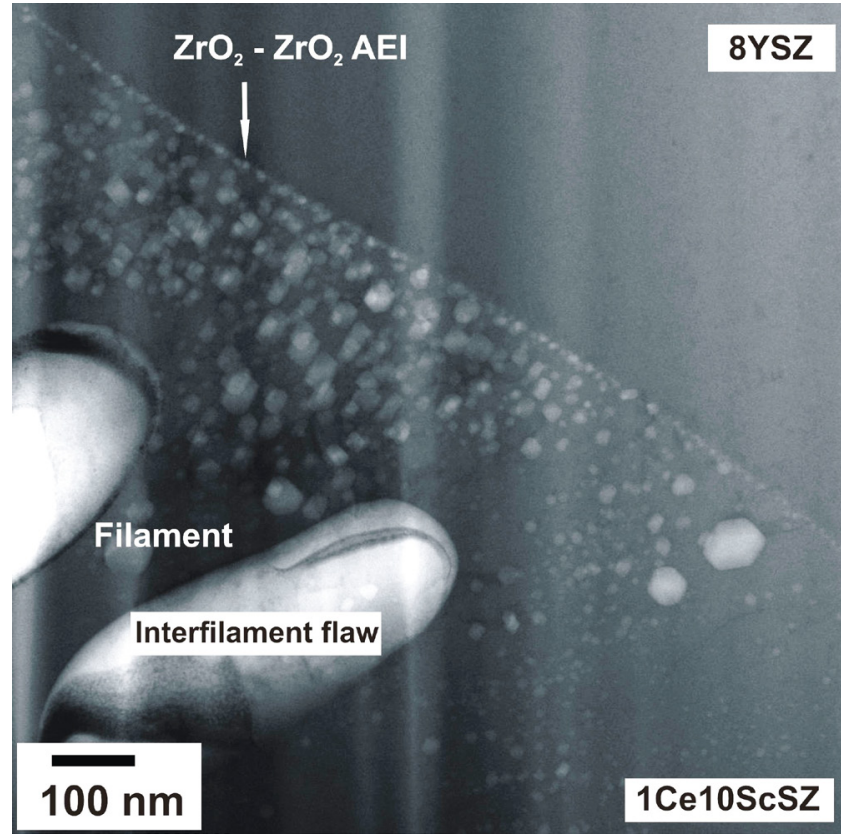

A

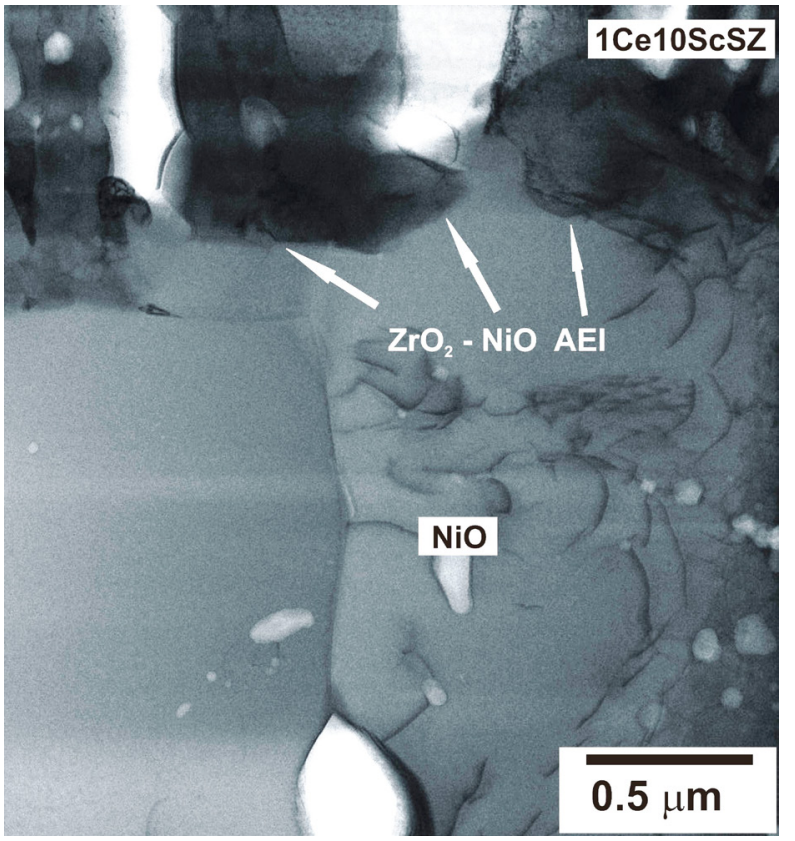

B

Figure 11. STEM micrographs of the anode - electrolyte interfaces (AEI) between 1Ce10ScSZ electrolyte film deposited on 8 YSZ (A) and NiO (B) grains of the porous $\mathrm{NiO}-\mathrm{ZrO}_{2}$ anode composite with $\mathrm{EB}-\mathrm{PVD}$ in the state after annealing at $1100{ }^{\circ} \mathrm{C}$ [29].

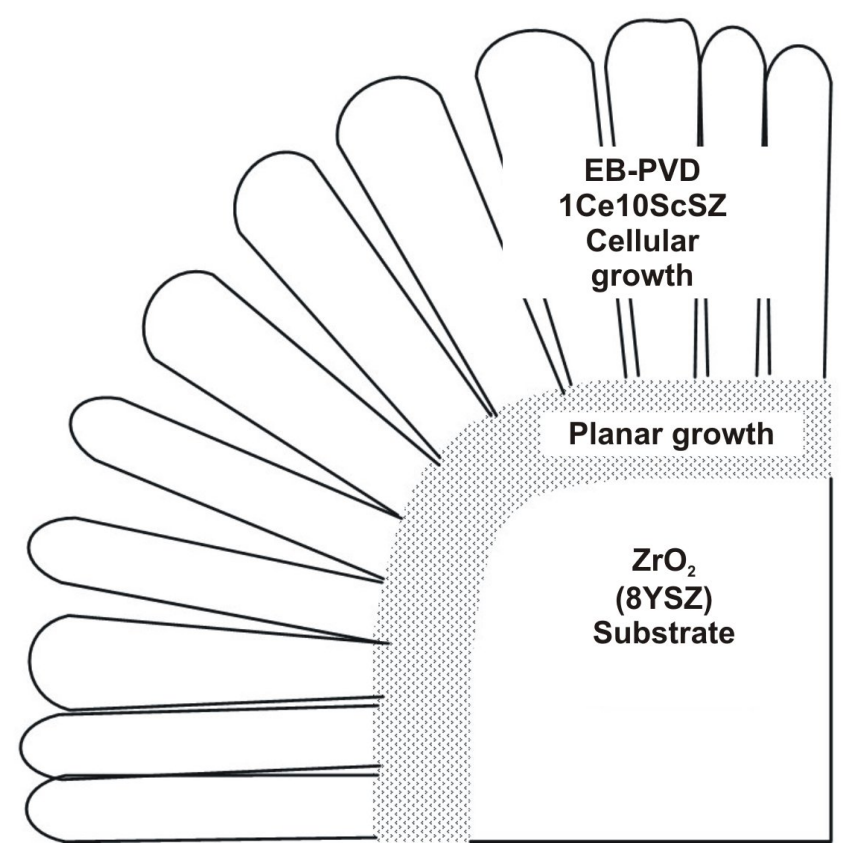

A



B

Figure 12. The schemes of the EB-PVD 1Ce10ScSZ structures observed on the 8YSZ (A) and the NiO (B) substrates [29].

The presented data clearly show that vapors of the $1 \mathrm{Ce} 10 \mathrm{ScSZ}$ compound (later - just as "zirconia" that also is meaning "cubic zirconia") produced with electron beam evaporation in a EB-PVD process condense on the two solid phases of the three phase substrate (two solid phases are $8 \mathrm{YSZ}$ and $\mathrm{NiO}$, the third one is pores) with two different mechanisms of the film nucleation and growth. By other words, zirconia is depositing and condensing on zirconium and nickel oxides in very different ways.

With respect to the condensation of zirconia on zirconia heated to $700-900{ }^{\circ} \mathrm{C}$ (that is around 0.3 to 0.4 of $\mathrm{ZrO}_{2}$ melting temperature in absolute temperatures) the following conclusions could be drawn:

Initially, the zirconia condenses on the smooth surface of 
zirconia grains presumably in terms of the Frank - Van der Merwe's "layer by layer" model [39]. It might be assumed that these layers are amorphous and have defects, i.e., the deposition of a first zirconia portion occurs as the "amorphous layer on an amorphous substrate" model. During annealing this amorphous defective layer crystallizes and pores are formed (Fig. 11A). The chain of these pores makes the $1 \mathrm{Ce} 10 \mathrm{ScSZ}-8 \mathrm{YSZ}$ AEI well visible. Pores are observed across the band of 0.3 to $0.5 \mu \mathrm{m}$ thickness where no other structural features are visible by TEM. Moreover, there is no visible order in the pore arrangement that could indicate any $3 \mathrm{D}$-island growth. The porous band appears to be non-coherent defective material that is not densified fully even during heat treatment at $1100^{\circ} \mathrm{C}$. In spite of the non-ideal structure of this porous band, it is followed by cells / filaments, which can be seen as evidence that the mechanism of film growth was planar and it might be termed as "defective layer by defective layer".

In terms of the condensation developed for solidification of the liquid phase, the planar growth is realized as perfectly pure material, whose purity is ensured by pushing outwards any alloying elements or impurities at the front of the solid-liquid interface (i.e. the phenomena of zone refinement [40]).

The solid-liquid interface moves as a planar surface in a direction opposite to the direction of heat removal pushing impurities ahead its front where they are accumulated afterwards. Eventually, their segregated amount may become critical, i.e. enough for the so-called constitutional supercooling that means literally that the thermal supercooling is reached locally for the portion of liquid, which is enriched by the segregating elements in comparison with the pure liquid.

As result, the growth mechanism will be changed. A few new cells / branches / filaments will be nucleated at the solidification front, which will jump ahead due to quick solidification of the enriched liquid portion. The latent heat of fusion will be released at this moment that will result in some stop of the solidification front and redistribution of a new portion of impurities. The planar growth will be replaced by the cellular one since new nuclei will be created and conditions for solidification are changed chemically, or constitutionally. A superposition of at least three physical phenomena namely the thermal supercooling, the fusion latent heat release and the constitutional supercooling occur. It results in structural and chemical heterogeneity, or laminarity, which is well-visible at the micro level in single crystals, metallic welds [41] and EB-PVD films as we could observe here (Figure 13). It is generally accepted that some technical instabilities are reasons for the laminar growth.

In full analogy with the solidification of the liquid phase, with the condensation of $\mathrm{ZrO}_{2}$ on a monocrystalline zirconia substrate (locally, within one $\mathrm{ZrO}_{2}$ grain of porous $\mathrm{NiO}-\mathrm{ZrO}$ composite) heated up to $700-900{ }^{\circ} \mathrm{C}$, we indeed see that zirconia initially condenses according to a planar mechanism and the material grows by "layer by layer" [39] up to about
$0.5 \mu \mathrm{m}$ thickness. The only visible structural feature of the material condensed during this stage is nanosized porosity that is revealed after annealing.

It means that the conditions, which are able to change the EB-PVD film growth mechanism, are reached at the $\sim 0.5 \mu \mathrm{m}$ film thickness. The planar mechanism is changed by a cellular one. New nuclei are visible. These nuclei transform into cells, which may grow, in our case, as long filaments across all the film thickness. They were nucleated like islands but not on the original $\mathrm{ZrO}_{2}$ substrate (zirconia grain) but the new zirconia film formed by the planar mechanism on the original zirconia substrate.

Beginning from this point, filaments grow in competition with their neighbors as branches of dendrites. The fact that filaments form as dendrite branches is seen in the flaws between the large bushes of filaments, tips of which have short secondary branches.

In planes of cleavage, broken filaments have spherical nodules on their tips, i.e. they look like heads of matches instead of being facetted that might be at a brittle fracture of zirconia. If this phenomenon could be observed on free surface like in an interbush flaw, these heads could evidence filament growth cessation, accumulation of admixtures, latent heat release and tip melting. But the "match heads" are observed in a dense bush body. In this case, fritted appearance of a broken filament tip may evidence a release of energy localized in nano-sized filament due to limited heat dissipation at its deformation before fracture similar to observed spheroids in metallic glasses [42].

In the course of their growth, the filaments create their own condensation laminarity, a collective picture of which is clearly seen on the polished cross-sections of bulk samples (Figure 9). The filaments bend to the vapor flow in order to grow like plants, which bend and turn to the sunlight in order to ensure their growth. As the filament is growing, conditions favoring supercooling may arise again; as a result, secondary filaments will nucleate on the tips of the primary ones.

So, the moment when the filament bush can be formed is approaching. Nevertheless, it has to be kept in mind, that in the very beginning, the cell-filaments arise perpendicularly to the substrate surface, which may result in the formation of a 'fan' around the substrate $\mathrm{ZrO}_{2}$ grain as can be seen in Fig. $11 \mathrm{~A}$ and sketched in Fig. 12A.

The high nano-porosity formed at the stage of planar growth of the $\mathrm{ZrO}_{2}$ layer on the $\mathrm{ZrO}_{2}$ substrate and observed in samples annealed at $1100{ }^{\circ} \mathrm{C}$ (Fig. 11A) cannot yet be explained consistently. This porosity might indicate the low density of the initial portions of condensed zirconia in high vacuum that act as reducing agent. The evidence of this may be the well-known fact that as-deposited zirconia coatings look grey, which is always interpreted as a result of an oxygen deficiency. Annealing in air eliminates this deficit; the zirconia film becomes transparent and shines brilliantly. As it can be seen in the TEM, though, this procedure is not able to densify zirconia produced at this stage. The initially deposited zirconia is loose and probably amorphous. It has a 
lot of defects, which may promote oxygen ionic conductivity. The reasons for this condensation behavior could be the comparatively low temperature of the substrate and, as a result, a high condensation rate. However, the circumstance that a vaporized zirconia deposits on the zirconia substrate, which has some oxygen deficit due to the deep vacuum conditions (we used $\sim 10^{-5} \mathrm{~Pa}$ vacuum free of hydrocarbons) and temperature of $700{ }^{\circ} \mathrm{C}$, is sufficient for the deposited zirconia to lose oxygen. Annealing just recrystallizes pores and makes them visible (defect annealing). Indeed, we see that annealed nanosized pores are well-facetted.

In the case of heterogeneous condensation of zirconia on the nickel oxide substrate, some different microstructural features can be seen, although the main conclusions on the growth of zirconia films with two (planar and cellular) mechanisms are confirmed here also.

The first distinction is that there is no initial continuous $\mathrm{ZrO}_{2}$ film that could grow with the planar mechanism along the whole surface of the $\mathrm{NiO}$ grain (Figs 11B, 12B) as it is observed at the $\mathrm{ZrO}_{2}-\mathrm{ZrO}_{2}$ deposition (Figs $11 \mathrm{~A}, 12 \mathrm{~A}$ ). Instead of "one" wide nucleus where the whole zirconia grain serves as the nucleus and zirconia condensates by "layer by layer" at the stage of the planar mechanism, a number of much smaller nuclei can be detected, more than a dozen in our case. It is possible to assume that these nuclei were initiated as "islands" but instead of lateral spreading in order to occupy the entire $\mathrm{NiO}$ grain surface, they grow in height. As a result, several separate crystals have been nucleated and grown on each $\mathrm{NiO}$ grain.

The second distinction is that the initial part of $\mathrm{ZrO}_{2}$ film grown on the $\mathrm{NiO}$ substrate by the planar mechanism has no any visible pores even after annealing (Fig 11B). As a result, the $\mathrm{ZrO}_{2}-\mathrm{NiO}$ AEI is hardly visible in comparison with the $\mathrm{ZrO}_{2}-\mathrm{ZrO}_{2}$ AEI.

Considering these features, the only might be concluded that these zirconia crystals are bushes of filaments, which have grown with two mechanisms also - planar and cellular growth. The very short trunk of the bush grows as the planar structure, and the branching filaments grow with the cellular mechanism. As result, no continuous band of planar growth exists. Instead of a band, islands of planar growth covered by a few cell / filaments are observed (Figs 11B,12B). The cells / filaments nucleate as a result of the constitutional supercooling in the frame of each planar island, thus, appearing as trunks of bushes. However, the islands do not spread along the entire $\mathrm{NiO}$ grain surface in order to occupy it completely. They had no enough material and time.

Talking about the sites of nucleation and orientation of the $\mathrm{ZrO}_{2}$ bushes on $\mathrm{NiO}$ substrates, we may say that they are sited on the curved surface of the $\mathrm{NiO}$ grain as terrace (Figures 11-13). They cover all the curved grain surface like trees on terraces of a steep hill, i.e. all the bushes have grown in one direction, likely [100], and on the same crystallographic planes, probably the $\{100\}$ family.

Using the botany terminology, we might say that the $\mathrm{ZrO}_{2}$ bush, which has grown on the $\mathrm{NiO}$ substrate has its "shoot and root systems" as a reconstruction shows in Fig. 5.
Its "shoot system" consists of a short ( $\sim 0.3$ to $0.7 \mu \mathrm{m})$ trunk like in shrub plants (1), on which a few branches (2) in form of filaments have nucleated and grown. As to the structure of the crown, it can be stated that it may be both monocrystalline (1) and polycrystalline (crowns in the central part of the picture). In the grains of polycrystalline zirconia trunks, structural domains are observed. Looking at how our 'bush' is joined to the ground, we see some "root system" according to the botany terminology. Moreover, near the interface surface, the trunk has some bulge like a nodule on the tree trunk near its root. The bush's "root" is probably "hidden" in some zone (3) surrounding the site of joining of the $\mathrm{ZrO}_{2}$ trunk with the $\mathrm{NiO}$ substrate that has some contrast gradient. The $\mathrm{NiO}$ twin was observed (4).

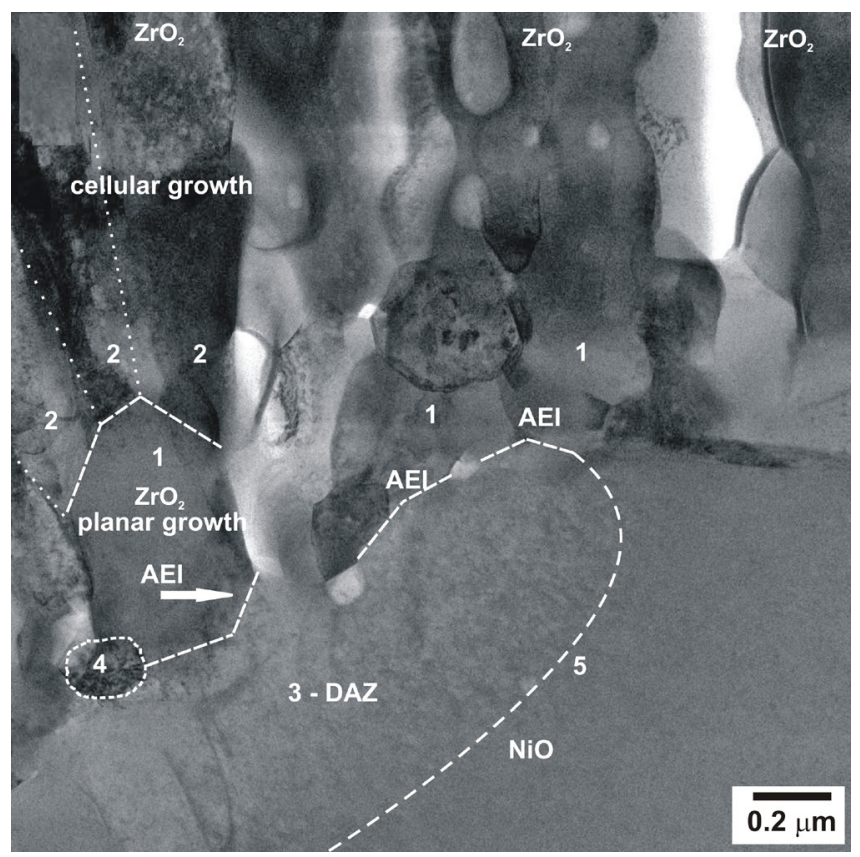

Figure 13. Schematic reconstruction of $\mathrm{ZrO}_{2}$ bush nucleation and growth on a $\mathrm{NiO}$ grain. The $\mathrm{ZrO}_{2}$ bush consists of a short trunk (1) grown in the course of planar growth and followed by a few branches (2) grown with the cellular mechanism as laminated cells/filaments. The laminarity results from the constitutional supercooling and technical instabilities occurring during their growth. The bush is sited on its deposition affected zone (3) of the $\mathrm{NiO}$ substrate and is separated from it by the hardly visible anode-electrolyte interface. 4 is the $\mathrm{NiO}$ twin. 5 is an imaginary boundary of the deposition affected zone stripe in the $\mathrm{NiO}$ substrate grain [29].

The zone, surrounding the $\mathrm{ZrO}_{2}$ bush base (band 3 in Figure 13), as a matter of fact, might be called as some "deposition affected zone (DAZ)" in full analogy with the "heat affected zone" (HAZ) that is widely used in a structural description of metallic welds. The HAZ is characterized by a typical structure of metal subjected to heat treatment by melted metal. As we can see, the similar situation exists during the deposition of $\mathrm{ZrO}_{2}$ vapor on $\mathrm{NiO}$ where the $\mathrm{DAZ}$ may be identified. The $\mathrm{NiO}$ zone adjacent to the crown of the $\mathrm{ZrO}_{2}$ bush has a structure that looks different from the rest of the $\mathrm{NiO}$ grain (Figures 10,13). This conclusion is confirmed additionally by the way of joining $\mathrm{ZrO}_{2}$ with $\mathrm{NiO}$. In the $\mathrm{ZrO}_{2}-\mathrm{ZrO}_{2}$ case, $\mathrm{ZrO}$ is placed on $\mathrm{ZrO}_{2}$ with no any 
indications of a strong interaction. Both the first layers of $\mathrm{ZrO}_{2}$ in planar growth and following $\mathrm{ZrO}_{2}$ cells / filaments of the cellular growth grow independently on orientation of the $\mathrm{ZrO}_{2}$ substrate. As a result, a fan of $\mathrm{ZrO}_{2}$ filaments is created (Figs $11 \mathrm{~A}, 12 \mathrm{~A}$ ). In the $\mathrm{ZrO}_{2}-\mathrm{NiO}$ case, the $\mathrm{ZrO}_{2}$ bush ingrows into the $\mathrm{NiO}$ grain. Moreover, all the $\mathrm{ZrO}_{2}$ bushes grow in one direction (probably [100]) in spite of the curvature of the $\mathrm{NiO}$ grain surface but they sit on the same planes, probably of the $\{100\}$ family.

These observations indicate the strong interaction between $\mathrm{ZrO}_{2}$ vapor and $\mathrm{NiO}$ substrate though an interaction between $\mathrm{ZrO}_{2}$ and $\mathrm{NiO}$ in the bulk is supposed to be weak. Conventional X-ray study does not detect any interaction.

The study of these phenomena in more details is still to be done, but now we might conclude that the observed differences in deposition of $\mathrm{ZrO}_{2}$ vapor on $\mathrm{ZrO}_{2}$ and $\mathrm{NiO}$ substrates are probably the result of differences in their melting temperatures $\left(\mathrm{T}_{\text {melt }}\right)$ that differ by almost $750{ }^{\circ} \mathrm{C}$. The EB-PVD process takes place at $0.32 \mathrm{~T}_{\text {melt }}$ for the $\mathrm{ZrO}_{2}-\mathrm{ZrO}_{2}$ system while for the $\mathrm{ZrO}_{2}-\mathrm{NiO}$ system it occurs at $0.42 \mathrm{~T}_{\text {melt }}$. For the solidification / condensation from the vapor, such differences are critical.

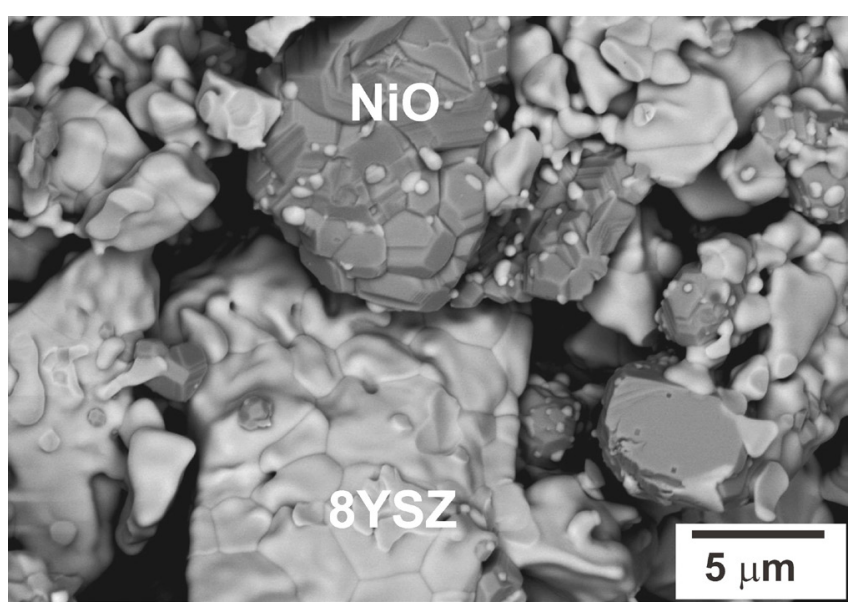

A

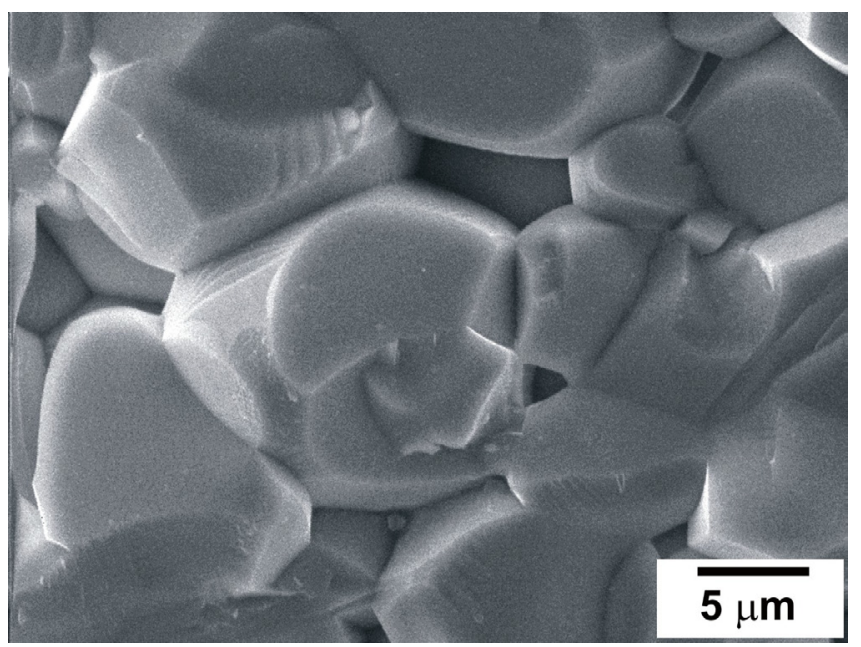

B

Figure 14. SEM pictures of fracture of NiO-8YSZ composite (A) and $1 \mathrm{Ce} 10 \mathrm{ScSZ}$ ceramics (B) [29].
Another reason concerns their different behavior in reducing (vacuum) atmosphere due to their large difference in oxygen affinity that causes different morphological changes, which are seen in the fracture surface of the $\mathrm{NiO}-\mathrm{ZrO}_{2}$ composite (Figure 9 and Fig. 14A). Probably zirconia is also promoting reduction of $\mathrm{Ni}$ when it is in contact with $\mathrm{NiO}$ at high vacuum and temperature that results in both faceting of $\mathrm{NiO}$ grains (cubic and hexagonal) and their reduction with formation of a $\mathrm{Ni}$ sponge. It can be seen that the surface of $\mathrm{ZrO}_{2}$ grains is smooth with no any sharp edges, which is especially surprising in comparison with the appearance of zirconia grains in pure zirconia ceramics without $\mathrm{NiO}$ (Fig. 14B). $\mathrm{NiO}$ grains, in contrast to those of $\mathrm{ZrO}_{2}$, are faceted revealing clearly outlined hexagonal syngony of rather large size (dozen of $\mu \mathrm{m}$ ). It is obvious that these morphological changes are the result of adsorption of NiO's oxygen by the zirconium. Amorphization of the zirconia grain surface may also be as an additional reason of their "as-fused" appearance.

The data obtained with transmission and scanning electron microscopy of the transitional zone between an EB-PVD zirconia film and its porous $\mathrm{NiO}-\mathrm{ZrO}_{2}$ substrate (anode electrolyte interface) allow formulating plausible mechanisms of the $\mathrm{ZrO}_{2}$ condensation from its vapor phase on $\mathrm{ZrO}_{2}$ and $\mathrm{NiO}$ substrates during the EB-PVD process:

In general, the $\mathrm{ZrO}_{2}$ condensation occurs in two stages with two mechanisms of growth - planar and cellular - by analogy with the solidification of the liquid.

The $\mathrm{ZrO}_{2}$ condensation on $\mathrm{ZrO}_{2}$ and $\mathrm{NiO}$ phases of the $\mathrm{NiO}-\mathrm{ZrO}_{2}$ composite occurs with two different routes.

Condensing on the $\mathrm{ZrO}_{2}$ phase at the planar growth stage, the $\mathrm{ZrO}_{2}$ film is covering the $\mathrm{ZrO}_{2}$ grain surface entirely by a continuous layer of $\sim 0.3-0.5 \mu \mathrm{m}$ thickness that is followed by dense long cells / filaments resulting from cellular growth. The layer of planar growth is very defective and probably amorphous. After annealing, it becomes nanoporous. The planar $\mathrm{ZrO}_{2}$ film on $\mathrm{ZrO}_{2}$ substrate might be termed as nucleated with the "defective layer by defective layer" mechanism. The cells / filaments nucleate on the planar layer with no visible orientational preference.

Condensing on the $\mathrm{NiO}$ phase at the planar growth stage, the $\mathrm{ZrO}_{2}$ film is discontinuous and porous. It consists of isolated "islands" / cells separated by rather big gaps / flaws, though the "islands" themselves have no visible density defects even after annealing. Having reached about 0.5 to 0.7 $\mu \mathrm{m}$ of length, the "islands" change their growth mechanism from planar to cellular one and secondary cells / filaments are nucleated similar to branches of a bush. The "islands" may be either monocrystalline or polycrystalline, but they are dense. It indicates that the "islands" could be formed with a "dense layer by dense layer" mechanism. But in contrast to the $\mathrm{ZrO}_{2}-\mathrm{ZrO}_{2}$ nucleation, the initial $\mathrm{ZrO}_{2}$ cells nucleated on $\mathrm{NiO}$ grow with well-visible orientational preference, probably [100], as if they are growing into the $\mathrm{NiO}$ substrating grain.

The deposition affected zone surrounding the nucleation site of $\mathrm{ZrO}_{2}$ on the $\mathrm{NiO}$ substrate is clearly discerned. It is a result of the entire phenomenon complex related to 
interaction of atoms and their clusters with a substrate in analogy with the heat affected zone in welding.

The structural features related to the $\mathrm{ZrO}_{2}$ root at the $\mathrm{ZrO}_{2}-\mathrm{NiO}$ interface may be responsible also for the high adhesion of zirconia films deposited on porous $\mathrm{NiO}-\mathrm{ZrO}_{2}$ composites with EB-PVD.

High density of the planar growth layers and the existence of the deposition affected zone as well as doping it with $\mathrm{Ni}$ are probably responsible for the increased elasticity modulus of the film areas bordering the anode-electrolyte interface.

Lateral growth of secondary branches / filaments and orientational independence of zirconia-on-zirconia growth are the reasons of good coverage of highly porous $\mathrm{NiO}-\mathrm{ZrO}_{2}$ composites by the dense zirconia film meeting SOFC requirement for He leakage.

\subsection{The Concept of Structural Optimization of CFC}

We see that during production, with both conventional and perspective techniques, and operation, CFC materials undergo degradation processes while under the combined influence of temperature, gas environment, contacts with inner and outer neighbors, electric current, mechanical stress, time etc. Traditionally, these processes are considered as negative and undesirable because they cause very serious structural alterations, chemical, which are related to local redistribution of chemical composition, and morphological, that not may not affect on their properties. At this, the effect is negative, and finally the CFC will degrade during operation.

The task is to prevent the drastic decrease of properties. We propose to transform the degradation processes into the useful instrument of positive changes, which will result in improvement of necessary properties of materials. By another words, we propose to optimize the structure of the CFC as a whole using the processes, which are responsible for negative effects in virgin CFC materials, in order to create the perfect $\mathrm{CFC}$, structure and properties of which will be unaltered for a long time of operation. Speaking more expressively, we propose to use degradational negative processes for the sake of a "positive degradation" in order to adjust the virgin materials and, thereby, provide the fuel cell by the stable optimal structure.

Such the replacement of the degradation from its negative to positive sense might be considered as an overall concept underpinning the structural optimization of CFC, which may have initially low or high but unstable properties, into a devices of stable structure, phase, geometrical and chemical, ensuring high performances. This "positive degradation" will make CFC of a high possible performance for operation during dozens of years at minimal maintenance.

As to the road-map how to reach the structural optimization, it is necessary to understand, which the approach of a suitable, optimized, structure might be accepted, the knowledge of degradation processes occurring in CFCs during their production and operation must be understood well. This knowledge would be gained from virgin materials, and as-produced and as-operated CFCs by means of traditional for materials science the comparative study and comprehensive structural characterization with various techniques such as electron microscopy and related techniques, X-ray phase analysis, nuclear magnetic and electron spin resonance spectroscopies, impedance spectroscopy of electrical resistivity etc. Because CFC is a laminar composite, the knowledge of its structural and chemical heterogeneity at initial and post-operational states and the comparison of both of them is essential for understanding the phenomena of degradation and using it with the goal of implementation of CFC long-term operation at high performance.

Also, the characterization of mechanical and electrical behaviors of CFC at material and system levels in different environments, temperatures, mechanical loadings and various redox and mechanical cycling is necessary. This knowledge would be obtained by long-term testing of fuel cells under realistic conditions with hydrogen, natural gas or bio-fuels at different temperatures and loadings in order to determine which fuel cell or technological process is more suitable for application and/or prescribed fuel. Because the CFC is a device of very long term operation and the research-pioneers are not able to wait the final result, the CFC degradation must be modeled appropriately in order to predict the behavior of the FC system.

For the electrolyte, as the first reference point for subsequent comparison, the zirconia powders of conventional composition, e.g., $1 \mathrm{Ce} 10 \mathrm{ScSZ}$, which are developed for electrolyte and electrodes, would be suitable. CFCs made of these virgin materials would be tested in order to obtain the reference data that jointly with data on structural and chemical heterogeneity, mechanical and electrochemical behaviors will be defined as the first reference point for the further iteration actions. Using these data and data already available including the literature ones, the parameters of zirconia powders will be refined for the second step of experiments, which will be repeated to optimize powders, their fine chemical composition and morphological features and the entire $\mathrm{CFC}$, via a few iteration steps. Three of them, we are hoping, would be enough to obtain the optimized CFC structure.

The chemical composition of powders will be optimized using iterative processes of substance transfer from initial virgin, powders into the electrolyte layer of the $\mathrm{CFC}$ laminated composite, which is changed by diffusion processes between CFC electrolyte and its electrode layers during CFC production and its long term operation. i.e. the final, corrected and optimized chemical composition of electrolyte layer and zirconia constituent in electrodes will be tuned by taking into account changes that occurs during both production and operation of the CFC in order to obtain longevity in the final product - the fuel cell system operating $600{ }^{\circ} \mathrm{C}$ or below.

Reducing the operating temperature to, e.g., $600{ }^{\circ} \mathrm{C}$, could positively impact on lifetime and costs of CFC systems, thereby facilitating the commercial introduction of clean and efficient CFC technology for heat and power generation.

Thus, the structural optimization is targeted for the radical improvement of ionic conductivity of the critical CFC cell 
component - the oxygen ionic conductor of electrolyte and electrodes - by using optimized $10 \mathrm{Sc} 1 \mathrm{CeSZ}$ zirconia powders tuned for long-term high ionic conductivity and stability in real materials, gas environments and electrical loads. The aim is to improve the ionic conductivity by a factor of minimum three in comparison with available materials on the world market.

It is understandable that the goals might be achieved by joint simultaneous highly qualified efforts in different disciplines including materials science first of all, chemistry, electrochemistry, thin films, mechanical behavior, catalysis and computer modeling. The working Program must include as follows: zirconia powder synthesis and sintering, thin film deposition with tape casting, and electron beam and magnetron sputtering deposition, comprehensive materials characterization with electron beam and related techniques, $\mathrm{X}$-ray, and nuclear magnetic and electron spin resonance techniques, mechanical and electrochemical behaviors at different mechanical and electric loads in different atmospheres and over time, impedance spectroscopy in a wide temperature interval, modeling and prediction. All the listed is very expensive research activity affordable mainly for the USA.

The main achievements, which led the authors to understanding that the ambitious intention of the CFC structural optimization would be realized, are as follows:

- The ionic conductivity of bulk and film electrolytes made of Ukrainian (Ukr, Type I) $1 \mathrm{Ce} 10 \mathrm{ScSZ}$ powders is $0.035 \mathrm{Scm}^{-1}$ at $700{ }^{\circ} \mathrm{C}$ instead of the $0.010 \mathrm{Scm}^{-1}$ obtained with the best powders traditionally used at international scale. Electrolytes made of Ukr powder has the highest strength (450 MPa), fracture toughness - 1.2-1.7 MPa $\mathrm{m}^{1 / 2}$, and so on. The Ukr electrolyte is much less inclined to recrystallization.

- The ionic conductivity of EB-PVD electrolyte films deposited onto a porous $\mathrm{NiO}-\mathrm{ZrO}_{2}$ anode substrate is much higher (half an order of magnitude) than of conventional layers deposited, e.g., by screen printing.

- CFC made with Ukr EB-PVD electrolytes were the first to pass the severe Juelich Research Center, Germany, standard for $\mathrm{He}$ leakage of $1.2 \cdot 10^{-04}$ to $9.3 \cdot 10^{-05}$ $\mathrm{mbar} \cdot \mathrm{l} /\left(\mathrm{sec} \cdot \mathrm{cm}^{2}\right)$.

- The processing of NiO- $\mathrm{ZrO}_{2}$ anode composites with low redox cycling results in significant improvement of the electrical conductivity and mechanical strength of the $\mathrm{Ni}-\mathrm{ZrO}_{2}$ anode cermet $[34,43]$.

- Porous materials sintered of some Ti in situ composite and Ti max-phase powders are stable in hydrogen and its mixtures at temperatures above $700{ }^{\circ} \mathrm{C}$ [44].

The structural optimization might be easily realized, if all the steps of a long CFC creation process could be united under one research project acting under the "from powder to power" concept, i.e., it begins from powder synthesis and completes by $\mathrm{CFC}$ testing via comprehensive structural characterization of powders and their transfer into CFCs, behavior characterization of their electrical and mechanical properties in different gas environment and at different mechanical and electrical loadings, catalytic activity both electrodes [45,46] and their new concepts [35,47], integration into technically relevant cells and stacks, and long-term tests.

Finally, at the last stage of the study, the stage of the "positive degradation", using data obtained for powders and CFC, materials will be modified and optimized in order to get a positive effect on the CFCs long-term performance at their usage in energy systems. The CFC, which has no any delaminating cracks along contacts between its structural parts that is very important for any electrotechnical device, might be elaborated (Figure 15). The laboratory fuel cells made of gadolinia doped ceria electrolyte have demonstrated $\sim 0.04 \mathrm{~W} / \mathrm{cm}^{2}$ being fueled by model gas -5 -vol. $\%$ with $\mathrm{Ar}$ at $650{ }^{\circ} \mathrm{C}$. I.e., with right designed electrodes, which could ensure the linear dependence of electric current on non-diluted hydrogen fuel, such the fuel cell may provide $\sim 0.80 \mathrm{~W} / \mathrm{cm}^{2}$ with $100 \%$ hydrogen. The available literature data shows $\sim 0.82 \mathrm{~W} / \mathrm{cm}^{2}$ as a typical power but at $750{ }^{\circ} \mathrm{C}$ [48].

The thermal expansion coefficients (TEC) of CFC materials are expected as follows [48,49]:

- 8 YSZ, $10 \mathrm{ScSZ}$ electrolytes, TEC $-\sim 10.5 \div 11.0 \mathrm{x}$ $10^{-6} /{ }^{\circ} \mathrm{C}$;

- $\mathrm{Ni}+\mathrm{YSZ}$ anode, TEC $\sim 12$ to $15 \times 10^{-6} /{ }^{\circ} \mathrm{C}$;

- $\mathrm{Sr}, \mathrm{Fe}$-doped $\mathrm{LaMnO}_{3}(\mathrm{LSM})+\mathrm{YSZ}$ cathode, TEC $\sim 10.5 \times 10^{-6} \%^{\circ} \mathrm{C}$;

- BaAlNbSi - glass-ceramic sealing, TEC - 13.5 x $10^{-6} /{ }^{\circ} \mathrm{C}$.

Some excess of electronic conductors thermal expansion over electrolyte one is obviously desirable for a contact conductivity improvement and is non-dangerous because electronic conductor is located in electrolyte pores.

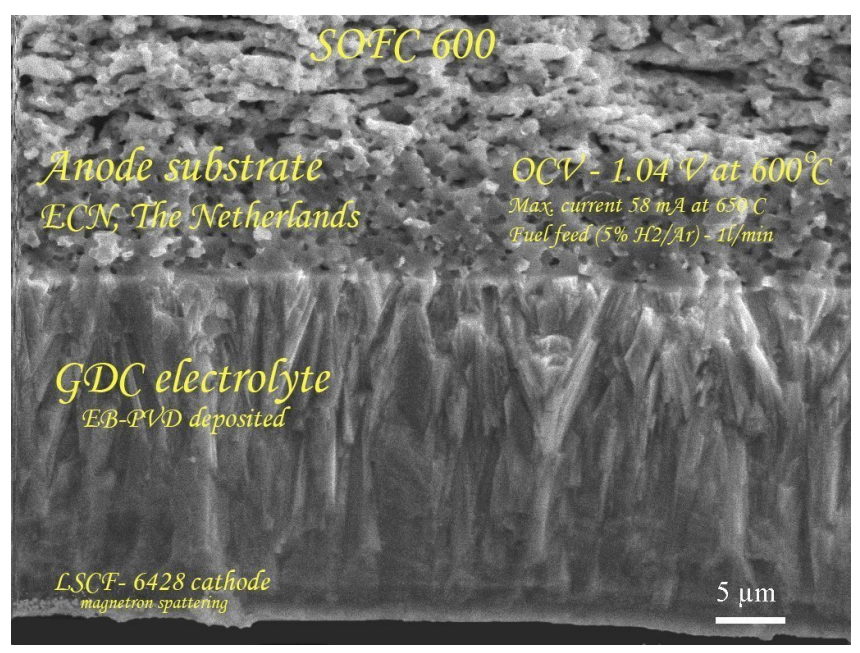

Figure 15. SEM picture of $\mathrm{CFC}$ fracture cross-section demonstrating the well-aligned GDC EB-PVD electrolyte to anode substrate made at the Energy Center of the Netherlands under the SOFC600 project [10]. No any delamination cracks along anode-electrolyte and cathode-electrolyte interfaces are observed. 


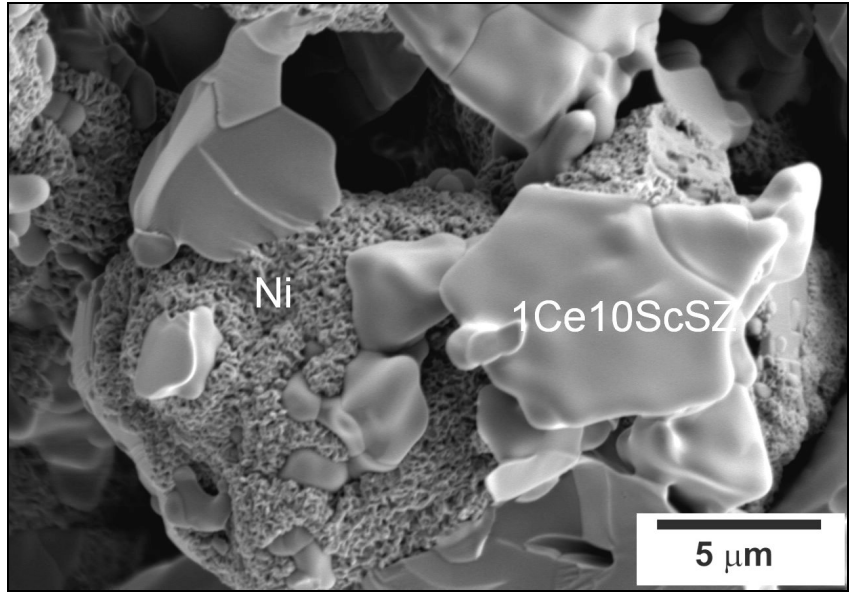

Figure 16. SEM picture of CFC fracture cross-section demonstrating well-suited to each other $1 \mathrm{Ce} 10 \mathrm{ScSZ}$ electrolyte and $\mathrm{Ni}$ conductor of the CFC anode processed with a low-cycle redox training [43].

The structure of $\mathrm{Ni}-\mathrm{ZrO}_{2}$ anode optimized with a redox training [43] and revealed with the fractured sample is shown in Figure 16. It is clearly seen that $\mathrm{Ni}$ and $\mathrm{ZrO}_{2}$ skeletons are well-suited to each other, providing the anode electrode high mechanical strength and electrical conductivity.

The CFC's technology is rather mature already and they might be put into commercial production now. Nevertheless, "The opportunities (for development) are endless" [50]. 3D printing is imminent.

For the last few years, we have witnessed major technological advances and competition of major energy companies within the evolving fuel cell market. General Electric, which was one of the fuel cell pioneers supplying energy for the first space missions, is planning now to enter a fuel cell market with their CFC system. GE has claimed a recent fuel cell breakthrough with an unprecedented electrical efficiency of $65 \%$ and an overall efficiency of up to $95 \%$ when the system is configured to capture heat produced by the fuel cell process that allowed GE to claim that "the resulting technology could soon start producing electricity around the world" [51].

\section{Conclusions}

The data accumulated in Laboratory for Ceramic Fuel Cells at Ukrainian Frantcevych Institute for Problems of Materials Science indicate undoubtedly that the structure of CFC might be optimized for purposes of both maximal efficiency and prolonged use.

For this goal, the concept of the "positive degradation" is proposed to be used in order to transform the degradation phenomena into an instrument for directional influence of degradation processes in virgin $\mathrm{CFC}$ materials enhancing and optimizing the CFC structure to be formed at both production and operation. The novel zirconia powders specially designed for electrolyte and both electrodes and structurally optimized entire CFC will be developed by a few iteration steps of materials and device tailorings along all the producing line from powders to power.

The data required in order to adjust initial composition and structure of zirconia powders and their electrolyte and both electrodes of the CFC, will be obtained studying as follows:

- Thin structure of the electrolyte film and their interfaces with anode and cathode, and distribution of chemical composition across the structure (structural \& chemical heterogeneity of electrolyte and its interfaces with electrodes), and its kinetics;

- The same for electrodes;

- The features of the structural \& chemical heterogeneity arising in the CFC laminated composites under thermal, redox and mechanical cycling;

- The area specific resistance and mechanical behavior of the CFC laminated composite under thermal, redox and mechanical cycling;

- Data on long-term CFC testing (at least $~ 500$ hours) to be obtained in real conditions at $600{ }^{\circ} \mathrm{C}$.

- EB-PVD technique is considered as a tool for refinement of CFC and enhancement of its performance and a way to creation of optimized $3 \mathrm{D}$ printed CFC.

Modeling of the temperature dependence of zirconia electrolyte ionic conductivity and prediction of changes during long-term operation via consideration of the cubic-rhombohedral transitions and recrystallization to be obtained with high temperature X-ray techniques. We anticipate that some new modified theory of temperature dependence of zirconia based electrolyte taking into account its phase transformations, initial powder particle and electrolyte structures, porosity will arise too.

\section{Acknowledgements}

We are very grateful to the National Academy of Science of Ukraine, their projects "Structural Fundamentals of Materials for Zirconia Ceramic Fuel Cells" and "SOFC structural optimization based on consideration of interdiffusion at manufacturing and operation", and current ones; NATO, their "Science for Peace" project $\mathrm{N}^{\circ} 980878$ "Solid Oxide Fuel Cells for Energy Security", the European FP6 projects: N ${ }^{\circ}$ SES6-2006-020089 "Demonstration of SOFC stack technology for operation at $600{ }^{\circ} \mathrm{C}$ (SOFC600)" and students exchange program of the "RealSOFC", INTAS project "Structure Optimization of SOFC Based on Scandia Doped Zirconia Ceramics for Space Application" for their respective support.

We are especially thankful our colleagues Prof. V. Vereshchak, Prof. O. Ostash, Dr. O. Koval, Dr. A. Samelyuk, Dr. A. Kotko, Dr. M. Beha, Dr. B. Vasyliv, Dr. A. Ivasyshyn, Dr. V. Podhurska, Mrs. M. Holovkova, Drs. I. and D. Brodnikovsky`s, Prof. J. Irvine, Prof. A. Smirnova, Prof. R. Steinberger-Wilckens, Prof. J. Kilner, Dr. C. Savaniyu, Dr. M. Andrzeichuk, Dr. J. Grzhonka, Prof. M. Levandowska, Prof. K. Kurzydlowski and Eng. B. Rietveld for their enthusiastic activity and support of obtaining new knowledge on ceramic fuel cell materials and their 
processing. We also appreciate Dr. Nina Orlovska for her assistance in initiation of the first international research project on CFC in Ukraine.

\section{REFERENCES}

[1] U.Bossel. The Birth of the Fuel Cell, 1835-1845. European Fuel Cell Forum, 2000.

[2] S. Srinivasan. Fuel Cells: From Fundamentals to Applications, Springer, 2006.

[3] H. Mobius. On the History of Solid Electrolyte Fuel Cells, J Solid State Electrochem. Vol. 1, 2-16, 1997.

[4] Ceramic Fuel Cells Handbook, Eds. R. Steinberger-Wilckens, O. Vasylyev. To be issued soon.

[5] K. Pointon, J. Irvine, A. Bonaccorso. Carbon-Fuelled Solid Oxide Cells for Military Applications. ECS Transactions, Vol.51, No.1, 141-153.

[6] E. Baur, and H. Preis. Uber Brennstoff-Ketten mit Festleitern. Z. Elektrochem. Vol. 43, No.9, 727-732.

[7] W. Nernst. Verfahren zur Erzeugung von Elektrischem Licht nach Patent 104872. D.R.P., 109907, 1898-06-19.

[8] W. Nernst. Die Nernst-Lampe. In: Mutter Erde. Technik, Reisen und Nützliche Naturbetrachtung in Haus und Familie. Verlag von W. Spemann, Berlin, 1899. Zweiter Band, S. 192 193 und S. 367 - 369, Online available from http://www.nernst.de/lamp/nernstlampe_me1899.

[9] W. Nernst. Memorial Website, Online available from http://www.nernst.de.

[10] Demonstration of SOFC Stack Technology for Operation at $600{ }^{\circ} \mathrm{C}$ (SOFC600). Online available from http://www.sofc6 00.eu.

[11] S.K. Lau, S.C. Singhal. Potential Electrode/Electrolyte Interactions in Solid Oxide Fuel Cells. Corrosion 85 (Boston, Massachusetts, 345/1, 1985 .

[12] T. Kawada, N. Sakai, H. Yokokawa and M. Dokiya. Reaction Between Solid Oxide Fuel Cell Materials. Solid State Ionics, Vol.50, 189-196.

[13] C.C. Appel. Zirconia stabilized by $\mathrm{Y}$ and $\mathrm{Mn}$ : A Microstructural Characterization. Ionics, Vol.1, No.5-6, 406-413.

[14] S. Linderoth and N. Bonanos. Effects of Dissolution and Exsolution of $\mathrm{Ni}$ in YSZ, Mater. Electrochem. Energy Convers. Storage, Vol.18, 147-56.

[15] Van Herle J., Vasquez R. Conductivity of Mn and Ni-doped stabilized zirconia electrolyte. Journal of the European Ceramic Society, Vol.24, No.6, 1177-1180.

[16] J. White, I.E. Reimanis, S. Menzer and G. Coors. The Enhanced Stabilization of the Cubic Phase in Yttria-Stabilized Zirconia with the Addition of Nickel Oxide. Journal of the American Ceramic Society, Vol.94, No.7, 2030-2036.

[17] L. P. Yurchenko, I. P. Bykov, A. B. Brik, O. Vasylyev, V.
Vereschak, G. Suchaneck, L. Jastrabik, A. Dejneka. Defect Structure of Nanosized Zirconium Oxide Powders Doped with $\mathrm{Y}_{2} \mathrm{O}_{3}, \mathrm{Sc}_{2} \mathrm{O}_{3}, \mathrm{Cr}_{2} \mathrm{O}_{3}$. Solid State Phenomena, Vol.200, 108-113.

[18] Y. Brodnikovskyi, N. McDonald, M. Brychevskyi, D. Brodnikovskyi, I. Brodnikovska, I. Polishko, L. Kovalenko, O. Vasylyev, R. Steinberger-Wilckens. Properties of 3.5YSZ/10Sc1CeSZ Ceramic Component for SOFC Anode Application. Solid State Ionics, to be published.

[19] O. Vasylyev, A. Smirnova, M. Brychevskyi, Ie. Pryshchepa, L. Dubykivskyi, A. Samelyuk, V. Vereschak, J. Malzbender. Zirconia EB-PVD Electrolyte Films: Structure, Mechanical Properties and Conductivity. ECS Transactions, Vol.25, No.2, 1687-1699.

[20] O. Vasylyev, A. Smirnova, M. Brychevskyi, I. Brodnikovskyi, S. Firstov, V. Vereshchak, G. Akimov, Yu. Komysa, J. Irvine, C.-D. Savaniu, V. Sadykov, I. Kosacki. Structural, Mechanical and Electrochemical Properties of Ceria Doped Scandia Stabilized Zirconia, Material Science of Nanostructures, Vol.1, 70-80.

[21] R. Steinberger-Wilckens, J. Mergel, A. Glusen K. Wippermann, I. Vinke, P. Batfalsky and M. Smith. Performance Degradation and Failure Mechanisms of Fuel Cell Materials. Institute of Energy Research, Germany, In: Materials for fuel cells, Ed. M. Gasik, Woodhead Publishing Ltd, 425-465, 2008.

[22] J. Grzonka, V. Vereshchak, O. Shevchenko, O. Vasylyev and K. Kurzydlowski. Characterization of $\mathrm{Sc}_{2} \mathrm{O}_{3} \& \mathrm{CeO}_{2}$-Stabilize d $\mathrm{ZrO}_{2}$ Powders via Co-Precipitation or Hydrothermal Synthesis. Microscopy and Microanalysis, Vol. 19, No.S5, 29-32. DOI online available fromhttp://dx.doi.org/10.1017/S 1431927613012270 .

[23] M. Brychevskyi, O. Vasylyev, Ye. Brodnikovskyi, S. Firstov, A. Samelyuk. Effect of Sintering Temperature on Structure and Mechanical Behavior of 1Ce10ScSZ Ceramics. Electron Microscopy and Strength of Materials. IPMS Annual Edition, Kyiv, No.19, 169-183, in Ukrainian.

[24] I. Brodnikovska, M. Brychevskyi, Ye. Brodnikovskyi, D. Brodnikovskyi, O. Vasylyev, A. Smirnova. On the Impedance Spectroscopy of Ceria Doped Scandia Stabilized Zirconia Solid Electrolyte. To be published.

[25] O. Kyrpa, O. Vasylyev, M. Brychevskyi, Y. Stovbun, A. Smirnova. On the Dependence of Oxygen Ionic Conductivity of $10 \mathrm{Sc} 1 \mathrm{CeSZ}$ Electrolytes on Temperature of Their Sintering. DOI: 10.13140/RG.2.1.3916.9360.

[26] D-S. Lee, W.S. Kim, S.H. Choi, J. Kim, H.-W. Lee, J.-H. Lee. Characterization of $\mathrm{ZrO}_{2}$ Co-Doped with $\mathrm{Sc}_{2} \mathrm{O}_{3}$ and $\mathrm{CeO}_{2}$ Electrolyte for the Application of Intermediate Temperature SOFCs. Solid State Ionics, Vol.176, 33-39.

[27] C. Haering, A. Roosen, H. Schichl, M. Schnfller. Degradation of the Electrical Conductivity in Stabilized Zirconia System. Part II: Scandia-Stabilized Zirconia, Solid State Ionics, Vol. $176,261-268$.

[28] M. Andrzejczuk, O. Vasylyev, M. Brychevskyi, A. Smirnova, M. Lewandowska, K. Kurzydłowski, R. Steinberger-Wilcke ns, J. Mertens and V. Haanappel. Structural Features and Gas Tightness of EB-PVD 1Ce10ScSZ Electrolyte Films, Matereials Science-Poland, DOI:10.2478/s13536-012-00250 , Online available from http://www.materials-science.pwr. wroc.pl/. 
[29] O. Vasylyev, M. Brychevskyi, I. Brodnikovskyi, S. Firstov, M. Andrzejczuk, M. Spychalski, M. Lewandowska, K. Kurzydlowski, R. Steinberger-Wilckens, J. Mertens, and J. Malzbender. Nucleation and Growth Mechanisms of Zirconia Film Deposited on Porous Nickel Oxide - Zirconia Substrate by Electron Beam - Physical Vapor Deposition. Advances in Ceramic Science and Engineering, Vol.3, 25-35.

[30] S. Linderoth, N. Bonanos, K. Jensen and J. Bilde-Sorensen. Effect of NiO-to-Ni Transformation on Conductivity and Structure of Yttria-Stabilized $\mathrm{ZrO}_{2}$. Journal of the American Ceramic Society, Vol.84, No.11, 2652-2656.

[31] J.V. Herle, R. Vasquez. Conductivity of Mn and Ni-Doped Stabilized Zirconia Electrolyte. Journal of the European Ceramic Society, Vol.24, 1177-1180.

[32] J. White, I. Reimanis. The Enhanced Stabilization of the Cubic Phase in Yttria-Stabilized Zirconia with the Addition of Nickel Oxide. J. Am. Ceram. Soc. 2011; 94(7): 2030-2036.

[33] O. Vasylyev, I. Brodnikovskyi, M. Brychevskyi, and I. Pryshchepa. NiO-10Sc1CeSZ anode: Structure and Mechanical Behavior. In: Advances in Solid Oxide Fuel Cells III: Ceramic Engineering and Science Proceedings, Volume 28, Issue 4, Narottam P. Bansal, Wiley, 361-67, 2007.

[34] O. Ostash, B. Vasyliv, V. Podhurska, O. Vasylyev, Ye. Brodnikovskyi, L. Ushkalov. The Optimization of 10Sc1CeSZ-NiO Composite with Redox Properties. Physics and Chemistry of Material Mechanics, Vol.2010, No.5, 76-81, in Ukrainian.

[35] I. Brodnikovskyi, The Regularities of Structure Formation, Mechanical Behavior and Electrochemical Properties of $\mathrm{Ni}-\mathrm{ZrO}_{2}$ Anode for Solid Oxide Fuel Cell. PhD Dissertation, IPMS, Kyiv, 21 p., 2012, in Ukrainian.

[36] R. Rice. Microstructure Dependence of Mechanical Behavior of Ceramics. Treatise on Mater. Science and Technology / Ed. R. K. MacCrone, Academic Press, NY, No.11, 199-381, 1977.

[37] R. Chaim. Activation Energy and Grain Growth in Nanocrystalline Y-TZP Ceramics. Materials, Sciience and Engineering, Vol.A, No.486, 439-446.

[38] F. C. Fonseca, R. Mucillo. Impedance Spectroscopy Analysis of Percolation in (Yttria-Stabilized Zirconia)-Yttria Ceramic Composites, Solid State Ionic, Vol.166, 157-165.

[39] M. Ohring. The Materials Science of Thin films, Academic Press, 1992.

[40] B. Chalmers. Principles of Solidification, New York, Wiley \& Sons, USA, 1964.
[41] A. Vasilyev. The Mechanical Properties of Single-Pass Weld Metal in Respect of Its Solidification, Proc. Intern. Conf., Weld Pool Chemistry \& Metallurgy, Welding Institute Reprint, London, UK, 3-8, 1980.

[42] D. Matthews, V. Ocelık, P. Bronsveld, and J. De Hosson. An Electron Microscopy Appraisal of Tensile Fracture in Metallic Glasses, Acta Materialia, Vol.56, 1762-1773.

[43] B. Vasyliv, O. Ostash, V. Podhurska, and O. Vasylyev. A Procedure of Treatment of NiO-Containing Anodes of Solid Oxide Fuel Cells, Patent of Ukraine, No.78992, April 10, 2013, in Ukrainian.

[44] O. Ostash, T. Prikhna, A. Ivasyshyn, V. Podhurska, T. Basyuk, O. Vasylyev, Ye. Brodnikovskyi. Heat Resistant Material for Fuel Cells, Patent of Ukraine, No.94545, November 11, 2014, in Ukrainian.

[45] V. Chedrik, A. Vasil'ev, S. Orlik. Effect of the Composition of Nickel-Containing Composites Based on Stabilized Zirconia on Catalytic Activity in Methane Steam Conversion. Theoretical and Experimental Chemistry, Vol.43, No.4, 261-265

[46] T. Shashkova, M. Kantserova, V. Chedryk, O. Vasylyev, S. Orlyk. Methane Oxidative Conversion over the Composites of Y- and Sc-Stabilized Zirconia Based. Polish Journal of. Chemistry, No.82, 371-376.

[47] L. Ushkalov, O. Vasylyev, Ie. Pryschepa, A. Samelyuk, V. Melakh. Synthesis and Study of LSCF Perovskites for IT SOFC Cathode Application. ECS Transactions, Vol.25, No.2, 2421-2426.

[48] Solid Oxide Fuel Cell Integrated Power Plant Development in North America, Solid Oxide Fuel Cells for next Generation Power Plants, Delft University of Technology, Versa Power Systems, Calgary, Alberta, Canada, http://dutw1479.wbmt.tu delft.nl/ sofcpowergen2011/Presentations/Borglum_TU\%20 Delft 23\%20June\%202011.pdf.

[49] F. Tietz. Thermal Expansion of SOFC Materials, Ionics, January 1999, Volume 5, Issue 1, pp 129-139.

[50] A. Sharma. Follow the Digital Thread: How GE's Off To See Profit In The Age Of Cheap Oil, Online available from http://www.gereports.com/follow-the-digital-thread-how-ges -off-to-see-profit-in-the-age-of-cheap-oil/.

[51] The New Power Generation: This Fuel Cell Startup Could Spark a Revolution. Online available from http://www.gereports.com/post/92454271755/the-new-powe r-generation-this-fuel-cell-startup/. 